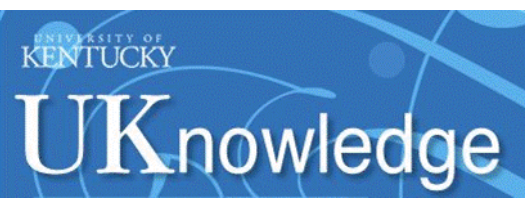

University of Kentucky

UKnowledge

\title{
Clinically Relevant Interactions between Newer Antidepressants and Second-Generation Antipsychotics
}

\author{
Edoardo Spina \\ University of Messina, Italy \\ Jose de Leon \\ University of Kentucky, jdeleon@uky.edu
}

Follow this and additional works at: https://uknowledge.uky.edu/psychiatry_facpub

Part of the Psychiatry and Psychology Commons

Right click to open a feedback form in a new tab to let us know how this document benefits you.

\section{Repository Citation}

Spina, Edoardo and de Leon, Jose, "Clinically Relevant Interactions between Newer Antidepressants and Second-Generation Antipsychotics" (2014). Psychiatry Faculty Publications. 42.

https://uknowledge.uky.edu/psychiatry_facpub/42

This Article is brought to you for free and open access by the Psychiatry at UKnowledge. It has been accepted for inclusion in Psychiatry Faculty Publications by an authorized administrator of UKnowledge. For more information, please contact UKnowledge@lsv.uky.edu. 
Clinically Relevant Interactions between Newer Antidepressants and SecondGeneration Antipsychotics

Digital Object Identifier (DOI)

http://dx.doi.org/10.1517/17425255.2014.885504

Notes/Citation Information

Published in Expert Opinion on Drug Metabolism \& Toxicology, v. 10, issue 5, p. 721-746.

(c) 2014 Taylor \& Francis Group

This is an Accepted Manuscript of an article published by Taylor \& Francis Group in Expert Opinion on Drug Metabolism \& Toxicology in May 2014, available online: http://www.tandfonline.com/10.1517/ 17425255.2014 .885504 
This is an Accepted Manuscript of an article published by Taylor \& Francis Group in Expert Opinion on Drug Metabolism \& Toxicology in May 2014, available online: http:// www.tandfonline.com/10.1517/17425255.2014.885504

\section{CLINICALLY RELEVANT INTERACTIONS BETWEEN NEWER ANTIDEPRESSANTS AND SECOND-GENERATION ANTIPSYCHOTICS}

Edoardo Spina ${ }^{1}$, Jose de Leon ${ }^{2}$

${ }^{1}$ Department of Clinical and Experimental Medicine, University of Messina, and ${ }^{2}$ University of Kentucky Mental Health Research Center at Eastern State Hospital, Lexington, KY, and Psychiatry and Neurosciences Research Group (CTS-549), Institute of Neurosciences, University of Granada, Granada, Spain.

Corresponding author: Prof. Edoardo Spina, Department of Clinical and Experimental Medicine, University of Messina, Policlinico Universitario, Via Consolare Valeria, 98125 Messina, ITALY Telephone: +390902213647 Fax: +390902213300 E-mail: espina@unime.it

\section{Acknowledgments}

The authors acknowledge Lorraine Maw, M.A., at the Mental Health Research Center at Eastern State Hospital, Lexington, KY, USA, who helped in editing the article.

\section{Declaration of interest}

No commercial organizations had any role in the writing of this paper for publication. In the past few years, Dr. Spina has participated in speakers/advisory boards and lectures supported by AstraZeneca, Bristol-Myers, Eli Lilly \& Co, Janssen Pharmaceuticals, Lundbeck and Pfizer. Dr. de Leon personally develops his presentations for lecturing, has never lectured using any pharmaceutical or pharmacogenetic company presentations, and has never been a consultant for pharmacogenetic or pharmaceutical companies. In the past, Dr. de Leon received researcherinitiated grants from Eli Lilly (one ended in 2003 and the other, as co-investigator, ended in 2007); from Roche Molecular Systems, Inc. (ended in 2007); and, in a collaboration with Genomas, Inc., from the NIH Small Business Innovation Research program (ended in 2010). He has been on the advisory boards of Bristol-Myers Squibb (2003/04) and AstraZeneca (2003). Roche Molecular Systems supported one of his educational presentations, which was published in a peer-reviewed 
journal (2005). His lectures were supported once by Sandoz (1997), twice by Lundbeck (1999 and 1999), twice by Pfizer (2001 and 2001), three times by Eli Lilly (2003, 2006, and 2006), twice by Janssen (2000 and 2006), once by Bristol-Myers Squibb (2006), and seven times by Roche Molecular Systems, Inc. (once in 2005 and six times in 2006). 


\begin{abstract}
\end{abstract}
Introduction: Combinations of newer antidepressants and second-generation antipsychotics (SGAs) are frequently used by clinicians. Pharmacokinetic and poorly understood pharmacodynamic drug interactions can occur between them. Areas covered: Limited pharmacodynamic drug interaction information and pharmacokinetic drug interaction studies are comprehensively reviewed. Expert opinion: More pharmacokinetic drug interaction studies are needed for better establishing dose correction factors after adding fluoxetine and paroxetine to aripiprazole, iloperidone and risperidone. More pharmacokinetic drug interaction studies and case reports are needed for better establishing the need for dose correction factors after adding i) fluoxetine to clozapine, lurasidone, quetiapine and olanzapine; ii) paroxetine to olanzapine; iii) fluvoxamine to asenapine, aripiprazole, iloperidone, lurasidone, olanzapine, quetiapine and risperidone; iv) high sertraline doses to aripiprazole, clozapine, iloperidone and risperidone: v) bupropion and duloxetine to aripiprazole, clozapine, iloperidone and risperidone; and vi) asenapine to paroxetine and venlafaxine. Possible beneficial pharmacodynamic drug interaction effects occur after adding SGAs to newer antidepressants for treatment-resistant major depressive and obsessivecompulsive disorders. The lack of studies combining newer antidepressants and SGAs in psychotic depression is worrisome. Pharmacodynamic drug interactions between newer antidepressants and SGAs may be more likely for mirtazapine and bupropion. Adding selective serotonin reuptake inhibitors (SSRIs) and SGAs may increase QTc interval and may very rarely contribute to torsades de pointes.

Keywords: newer antidepressants, second-generation antipsychotics, drug interactions, pharmacodynamics, pharmacokinetics 


\section{Highlights box}

- Drug-drug interactions between newer antidepressants and second-generation antipsychotics (SGAs) are frequently clinically relevant.

- More pharmacokinetic drug interaction studies are needed for better establishing dose correction factors after adding fluoxetine and paroxetine to aripiprazole, iloperidone and risperidone.

- More pharmacokinetic drug interaction studies and case reports are needed for better establishing the need for dose correction factors after adding i) fluoxetine to clozapine, lurasidone, quetiapine and olanzapine; ii) paroxetine to olanzapine; iii) fluvoxamine to asenapine, aripiprazole, iloperidone, lurasidone, olanzapine, quetiapine and risperidone; iv) high sertraline doses to aripiprazole, clozapine, iloperidone and risperidone; v) bupropion and duloxetine to aripiprazole, clozapine, iloperidone and risperidone; and vi) asenapine to paroxetine and venlafaxine.

- The pharmacodynamic science of drug interactions between newer antidepressants and SGAs is in its infancy.

- There are possible beneficial pharmacodynamic drug interaction effects after adding SGAs to newer antidepressants for treatment-resistant major depressive disorder and obsessive-compulsive disorder (OCD). The lack of studies in psychotic depression using combinations of newer antidepressants and SGAs is worrisome.

- Pharmacodynamic drug interactions between newer antidepressants and SGAs may be more likely for mirtazapine and bupropion. Clinicians need to remember that adding selective serotonin reuptake inhibitors (SSRIs) and SGAs may risk an increase in QTc interval and very rarely contribute to torsades de pointes. 


\section{Introduction}

Drugs used for the treatment of depressive disorders are usually classified into older or classic agents, such as tricyclic antidepressants (TCAs) and monoamine oxidase inhibitors (MAOIs), and newer antidepressants, such as selective serotonin reuptake inhibitors (SSRIs), serotonin and noradrenaline reuptake inhibitors (SNRIs) and other antidepressants with variable mechanisms of action [1]. Over the past two decades, newer antidepressants, particularly SSRIs, have gradually replaced TCAs as drugs of choice for the management of depressive disorders, mainly because of their improved tolerability and safety profile. Some newer antidepressants are also approved for the treatment of other psychiatric conditions including anxiety disorders, obsessive compulsive disorder, eating disorders, and various forms of chronic pain such as diabetic neuropathic pain and fibromyalgia [1].

Antipsychotic drugs can be similarly divided into traditional or first-generation antipsychotics (FGAs) and atypical or second-generation antipsychotics (SGAs) [2]. In recent years, SGAs have become the mainstream treatment intervention for patients with schizophrenia and bipolar disorder, due to a lower risk for acute and chronic extrapyramidal symptoms and prolactin elevation, as compared to traditional antipsychotics. They are also increasingly used to treat a variety of psychiatric and neurological disorders including mental and behavioral disorders in dementia, psychosis associated with Parkinson's disease, treatment-resistant obsessivecompulsive disorder (OCD), and aggressive behavior [3]. However, antiserotonergic SGAs, such as clozapine, appear to be associated with a risk of inducing or aggravating obsessive-compulsive symptoms in schizophrenia [4].

Newer antidepressants and SGAs are often prescribed together in patients with concomitant psychotic and depressive symptoms, such as those with schizoaffective disorder [5] or psychotic depression [6]. Moreover, antidepressants, mainly SSRIs, may be used as an adjunctive strategy for the treatment of negative symptoms of schizophrenia [7,8]. On the other hand, SGAs may be added to antidepressants in patients with refractory OCD [9-11] and in those with treatment-resistant major depressive disorder [12-14]. In this respect, aripiprazole and quetiapine extended-release received United States (US) Food and Drug Administration (FDA) approval as add-ons for patients with major depressive disorder, while the combination olanzapine-fluoxetine was approved for treatment-resistant depression.

In view of the frequent co-prescription of newer antidepressants and SGAs, sometimes for the purpose of augmentation, information on potential drug interactions between these compounds is important for safe prescribing. While certain drug combinations may prove beneficial and, 
therefore, may be used advantageously in clinical practice, in many cases they may be harmful, resulting in either decreased efficacy or increased risk of adverse drug reactions (ADRs).

In recent years, a number of comprehensive reviews of clinically relevant DIs involving newer antidepressants [15-18] or SGAs have been published [19-22]. The aim of the present article is to provide an updated review of clinically significant drug interactions between newer antidepressants and SGAs.

Articles for this review were obtained from a PubMed search with no time limit. Searches were performed for each of the newer antidepressants and SGAs. Only articles published in peerreviewed journals were included, while meeting abstracts were excluded. Information was also obtained from the individual product inserts of each newer antidepressant or SGA. Additional drug interaction information was also obtained from citations of the articles that were retrieved during our search, and these were also included in our review. This search was beyond the articles previously found and listed in the authors' published literature reviews [16, 19] and drug interaction studies.

\section{Basic mechanisms of drug interactions between newer antidepressants and SGAs}

Based on their mechanisms, drug interactions are usually divided into two categories, pharmacokinetic and pharmacodynamic.

\subsection{Pharmacokinetic drug interactions}

Pharmacokinetic drug interactions consist of changes in the absorption, distribution, metabolism or excretion of a drug and/or its metabolite(s) after the addition of another drug. These drug interactions are easily verified by a change in plasma drug concentrations, usually called therapeutic drug monitoring (TDM). Pharmacokinetic parameters of newer antidepressants and SGAs are summarized in Tables 1 and 2, respectively.

Drug interactions can occur at the gastrointestinal level when medications are administered orally, which is always the case with newer antidepressants and frequent with SGAs. To our knowledge, no interaction at the oral absorption level has been described so far between these two drug types.

Protein binding displacement interactions may theoretically occur between newer antidepressants and SGAs, as many of these agents are highly bound to plasma proteins ( $>90 \%)$. Competition between two drugs for binding sites on plasma proteins may cause a rise in the free fraction of the displaced drug in plasma or tissue, thereby potentially increasing its pharmacological 
effects [23]. However, unless additional mechanisms are at work, these interactions are usually not clinically relevant, because the free drug is rapidly cleared from the plasma.

Most pharmacokinetic drug interactions between newer antidepressants and SGAs occur at a metabolic level and usually involve the hepatic cytochrome P450 (CYP) system and, to a lesser extent, the uridine diphosphate glucuronosyltransferase (UGT) system [24]. In recent years, the in vitro characterization of the major drug-metabolizing enzymes, in particular the human CYP system, with identification of substrates, inhibitors, and inducers of different CYP isoforms, has greatly improved the prediction of metabolic drug interactions, providing an invaluable resource in helping to anticipate and avoid potential drug interactions [24]. In principle, concomitant treatment with drugs metabolized by the same enzyme or coadministration of a drug with another medication acting as an inhibitor or inducer involves the risk of a drug interaction. The potential occurrence and clinical significance of a metabolic drug interaction will then depend on a variety of drug-related (i.e., potency and concentration/dose of the inhibitor/inducer, therapeutic index of the substrate, extent of metabolism of the substrate through the affected enzyme, presence of active metabolites), patient-related (i.e., age, genetic predisposition) and environmental factors (i.e., smoking) [23]. As shown in Tables 1 and 2, newer antidepressants and SGAs (with the exception of amisulpride and paliperidone) are extensively metabolized via CYPs or UGTs. As many compounds of these two therapeutic classes share common metabolic pathways, potential metabolically-based drug interactions may be anticipated. Furthermore, some newer antidepressant agents act as inhibitors of various CYPs and may therefore impair the elimination of antipsychotic agents metabolized via these isoforms $[15,16,18]$. On the other hand, most SGAs appear to be neither inhibitors nor inducers of the major drug-metabolizing enzymes [19, 21]; only asenapine may have weak CYP2D6 inhibitory properties that may become clinically relevant in some circumstances $[25,26]$.

Drug interactions at the renal excretion level are probably not relevant because both newer antidepressants and SGAs are mainly eliminated by drug metabolism.

Pharmacokinetic drug interactions between newer antidepressants and SGAs may also involve drug transporters, in particular P-glycoprotein (P-gp), which plays an important role in the absorption, distribution and excretion of a wide variety of therapeutic agents [27]. P-gp is encoded by the ATP-binding cassette sub-family B member 1 (ABCB1) gene. It is a multidrug efflux transporter highly expressed in the small intestine, brain, liver and kidney. It acts as a natural defense mechanism against several drugs by limiting their absorption from the gut and penetration into the brain and promoting their elimination in the bile and urine. A number of newer antidepressants, including the SSRIs fluoxetine, fluvoxamine, paroxetine and sertraline [28], as well as many SGAs, such as risperidone, paliperidone, olanzapine, aripiprazole and ziprasidone, are 
substrates of P-gp [29]. Moreover, in vitro studies have indicated that some newer antidepressants, namely paroxetine, fluvoxamine and sertraline, and the SGAs olanzapine and risperidone may also act as P-gp inhibitors [30]. Based on this evidence, it cannot be excluded that some pharmacokinetic drug interactions between newer antidepressants and SGAs, currently attributed to metabolic enzyme inhibition, may also be explained by P-gp inhibition.

\subsection{Pharmacodynamic drug interactions}

Most articles reviewing drug interactions ignore the pharmacodynamic mechanisms of newer antidepressants and SGAs, which are poorly understood. This subsection provides a very brief reference to the pharmacodynamics of antidepressants and SGAs; they are described more comprehensively in Figures 1 to 4 and their detailed footnotes. At the end of this section, a subsection comments on the types of pharmacodynamic drug interactions.

\subsubsection{Antidepressant pharmacodynamics}

Figure 1 summarizes antidepressant mechanisms of action in several disorders including depression, OCD, anxiety, pain, and weight loss. Textbooks usually report that most new antidepressants act by inhibiting reuptake transporters, but they also usually acknowledge that this is not a definitively proven theory, since the chronology of reuptake inhibition does not match the chronology of antidepressant response. SSRIs include fluoxetine, paroxetine, fluvoxamine, sertraline, citalopram and escitalopram; the name SSRI indicates that they mainly inhibit serotonin transporters. SNRIs inhibit both serotonin and noradrenaline transporters and include venlafaxine, desvenlafaxine, duloxetine, levominalcipran, and milnacipran. Other newer antidepressants with different mechanisms of action include reboxetine, bupropion, vilazodone, vortioxetine, mirtazapine, and agomelatine. Reboxetine is a selective noradrenaline transporter inhibitor. Bupropion is an inhibitor of noradrenaline and dopamine transporters. There is no agreement in the literature about mirtazapine's mechanism of action. Vilazadone [31] and recently-introduced vortioxetine [32] have SSRI properties and also are antagonists of some serotonin receptors. Vilazadone is also a 5-HT $1 \mathrm{~A}$ receptor antagonist and vortioxetine is also a $5-\mathrm{HT}_{3 \mathrm{~A}}$ and $5-\mathrm{HT}_{7}$ receptor antagonist, a 5- $\mathrm{HT}_{1 \mathrm{~B}}$ receptor partial agonist, and a $5-\mathrm{HT}_{1 \mathrm{~A}}$ receptor agonist (Figure 1, footnote 3). Labbate et al. [33] list mirtazapine as an alpha $2\left(\alpha_{2}\right)$ adrenergic receptor antagonist but also recognize that it has $5-\mathrm{HT}_{2 \mathrm{~A}}$ and $5-\mathrm{HT}_{2 \mathrm{C}}$ antagonist properties. Other articles and/or textbooks endorse other variants of this theory. Agomelatine is a melatonergic analogue drug acting as $\mathrm{MT}_{1} / \mathrm{MT}_{2}$ agonist and a 5-HT $2 \mathrm{C}$ antagonist [34]. 
Nefazadone and trazadone are not included in order to simplify this article. Nefazadone is no longer used and trazadone is frequently used as a hypnotic rather than an antidepressant agent.

Figure 2 summarizes antidepressant mechanisms of action associated with major safety issues.

\subsubsection{SGA pharmacodynamics}

Figure 3 summarizes SGA mechanisms of action, explaining their efficacy in schizophrenia, other psychoses and other psychiatric disorders [35]. In summary, the majority of the SGAs are dopamine 2 receptor $\left(\mathrm{D}_{2}\right)$ antagonists including amisulpride, asenapine, clozapine, iloperidone, lurasidone, olanzapine, paliperidone, quetiapine, risperidone, and ziprasidone, while aripiprazole is a $\mathrm{D}_{2}$ partial agonist. Many SGA ADRs are explained by their blockade of neurotransmitter receptors (Figure 4).

\subsubsection{Pharmacological knowledge and pharmacodynamic drug interactions}

Pharmacodynamic drug interactions take place directly at the site of action of a drug or indirectly by interfering with another physiological mechanism. They result in a modification of the pharmacological action of a drug without any change in the plasma concentration and are more difficult to identify and measure than pharmacokinetic drug interactions. These drug interactions can be additive (i.e., equal to the sum of the effects of the individual drugs), synergistic (i.e., the combined effects are greater than expected from the sum of individual effects) or antagonistic (i.e., the combined effects are less than additive) [23]. They can be associated with positive effects (increased efficacy and/or safety) or negative effects (decreased efficacy and/or safety).

\section{Specific drug interactions between newer antidepressants and SGAs}

\subsection{Pharmacokinetic interactions}

\subsubsection{Effect of newer antidepressants on the pharmacokinetics of SGAs}

\subsubsection{SSRIs}

At the present, SSRIs are the most widely prescribed antidepressants. They may cause clinically relevant, dose-dependent inhibition of various CYPs. The six marketed compounds differ considerably in their potency to inhibit individual CYP isoenzymes [16, 36].

\section{Fluoxetine}

Fluoxetine and its metabolite norfluoxetine are potent inhibitors of CYP2D6 and moderate inhibitors of CYP2C9, while they mildly to moderately affect the activity of CYP2C19 and 
CYP3A4 $[16,36]$. Based on this, fluoxetine is expected to interfere with the elimination of SGAs metabolized via these CYP isoforms.

Early pharmacokinetic studies had documented that fluoxetine may impair the elimination of clozapine resulting in an increase of approximately $40-70 \%$ of its plasma concentrations in patients concomitantly treated with fluoxetine $20 \mathrm{mg}$ /day [37, 38]. In a subsequent investigation, the effect of an 8-week treatment with fluoxetine $(20 \mathrm{mg} /$ day $)$ on plasma concentrations of clozapine and its active metabolite norclozapine was evaluated in 10 schizophrenic patients stabilized on clozapine therapy (200-450 mg/day) [39]. During fluoxetine administration, mean plasma concentrations of clozapine and norclozapine increased significantly $(p<0.01)$ by $58 \%$ and $36 \%$, respectively. A study controlling other variables estimated that fluoxetine increases plasma clozapine concentration by $36 \%$ on average, which requires multiplying the clozapine dose by 0.73 to compensate [40]. This interaction may be attributed to the inhibitory effect of fluoxetine on the activity of CYP2D6, CYP2C19 and CYP3A4, which play an important role in clozapine metabolism. In addition, norfluoxetine, the major metabolite of fluoxetine, may also contribute to this interaction as a moderate inhibitor of CYP3A4.

A clinically relevant pharmacokinetic drug interaction may occur between fluoxetine and risperidone. In an open-label study involving 10 schizophrenic patients stabilized on risperidone (4$6 \mathrm{mg} /$ day), coadministration of fluoxetine (20 mg/day) for 4 weeks caused a significant elevation (by $75 \%$; $\mathrm{p}<0.01$ ) of plasma concentration of the active fraction of risperidone (risperidone plus 9hydroxyrisperidone) [41]. One patient dropped out after one week of combination treatment due to occurrence of akathisia, while two patients developed parkinsonian symptoms, thus requiring anticholinergic medication. Bondolfi et al. [42] investigated the pharmacokinetics of risperidone (4 or $6 \mathrm{mg}$ /day) before and during coadministration of fluoxetine $(20 \mathrm{mg} /$ day $)$ in 11 psychotic inpatients, 8 of which were extensive metabolizers (EM) and 3 poor metabolizers (PM) for CYP2D6. The area under the plasma concentration/time curve (AUC) of the active moiety of risperidone increased from $470.0 \pm 170.0 \mathrm{ng} . \mathrm{h} / \mathrm{ml}$ to $663.0 \pm 243.3 \mathrm{ng} . \mathrm{h} / \mathrm{ml}(\mathrm{p}<0.05)$ and from $576.3 \pm 19.6 \mathrm{ng} . \mathrm{h} / \mathrm{ml}$ to $788.0 \pm 89.1 \mathrm{ng} . \mathrm{h} / \mathrm{ml}$ (not significant) in EMs and PMs, respectively. This interaction is presumably due to inhibition of CYP2D6, the major isoenzyme responsible for the 9hydroxylation of risperidone, although it is possible that norfluoxetine may also inhibit CYP3A4, blocking both metabolic pathways for risperidone. A reduction in risperidone dosage is advisable in case of concomitant administration of fluoxetine.

Coadministration of fluoxetine, $60 \mathrm{mg} /$ day, given for eight days to 15 non-smoking healthy volunteers caused a statistically significant, but clinically insignificant, change in the 
pharmacokinetic profiles of a single $5 \mathrm{mg}$ dose of olanzapine [43]. Olanzapine plasma clearance decreased by $15 \%(p<0.01)$ and peak plasma concentration $\left(C_{\max }\right)$ increased by $18 \%(p<0.01)$.

In a study of 13 patients with various psychiatric disorders treated with quetiapine, $300 \mathrm{mg}$ twice daily, the addition of fluoxetine, $60 \mathrm{mg} /$ day, for only 8 days did not substantially alter the $\mathrm{AUC}_{0-12 \mathrm{~h}}$ and the $\mathrm{C}_{\max }$ of quetiapine [44]. A large TDM study provided similar results, showing that concomitant administration with fluoxetine did not affect dose-normalized serum concentrations of quetiapine [45].

In patients comedicated with CYP2D6 inhibitors (including 9 subjects on fluoxetine) dosenormalized serum concentrations of aripiprazole were $45 \%$ higher compared with controls $(\mathrm{p}<0.05)$, while those of the active metabolite, dehydroaripiprazole were unchanged [46]. As aripiprazole is metabolized by CYP2D6 and CYP3A4, the inhibitory effect of fluoxetine on the activity of these two isoforms may account for the observed changes.

Iloperidone is metabolized by CYP2D6 and CYP3A4. According to its prescribing information, coadministration of fluoxetine (20 mg twice daily for 21 days) and a single $3 \mathrm{mg}$ iloperidone dose to $23 \mathrm{EM}$ healthy volunteers increased the AUC of iloperidone and its main metabolite P88 by about 2-3 fold, and decreased the AUC of its metabolite P95 by one-half. Iloperidone doses should be reduced by one-half when administered with fluoxetine $[25,26]$.

A recent case report documented the occurrence of a glossopharyngeal dystonia following coadministration of fluoxetine with lurasidone [47]. This effect was attributed to the inhibitory action of fluoxetine and norfluoxetine on CYP3A4-mediated biotransformation of lurasidone.

\section{Paroxetine}

Paroxetine is a potent inhibitor of CYP2D6, while it only minimally affects other CYPs [16, 36].

Paroxetine effects upon risperidone disposition were documented in two clinical pharmacokinetic investigations [48, 49]. In the first study involving 10 schizophrenic patients stabilized on risperidone therapy (4-8 $\mathrm{mg}$ /day), coadministration of paroxetine $(20 \mathrm{mg} /$ day) for 4 weeks resulted in a mean, statistically significant increase by $45 \%(\mathrm{p}<0.05)$ in plasma concentrations of the active fraction of risperidone [48]. The drug combination was well tolerated with the exception of one patient who developed extrapyramidal symptoms in the second week of adjunctive therapy. In the second study, 12 schizophrenic patients receiving risperidone $4 \mathrm{mg} / \mathrm{day}$ were, in addition, treated with incremental doses of paroxetine for 12 weeks (10, 20 and $40 \mathrm{mg} / \mathrm{day}$ for 4 weeks each) [49]. Paroxetine resulted in a dose-dependent increase in risperidone and active moiety plasma concentrations without changing 9-hydroxyrisperidone levels. Plasma concentrations of risperidone active moiety were not increased during paroxetine $10 \mathrm{mg} / \mathrm{day}(1.3-$ 
fold, not significant) or $20 \mathrm{mg} /$ day (1.6-fold, not significant) dosing, but were significantly increased by 1.8 -fold $(\mathrm{p}<0.05)$ during paroxetine $40 \mathrm{mg} /$ day dosing. This pharmacokinetic interaction is probably explained by the inhibitory effect of paroxetine on the CYP2D6-mediated 9hydroxylation of risperidone. An initial low dose of paroxetine (10 or $20 \mathrm{mg} /$ day) may be safe whenever paroxetine is coadministered with risperidone.

Data concerning the possibility of a metabolic interaction between paroxetine and clozapine are contradictory. Some studies have documented a moderate elevation of plasma clozapine concentrations (by approximately 20-40\%), presumably not associated with clinically relevant effects, following administration of therapeutic doses of paroxetine, $20 \mathrm{mg} / \mathrm{day}[38,50]$. A study controlling other variables estimated that paroxetine increased plasma clozapine concentration on average by $30 \%$ which requires multiplying the clozapine dose by 0.77 to compensate [38]. This effect has been attributed to the inhibition of CYP2D6, an isoform which is partially responsible for clozapine biotransformation. Conversely, another investigation has documented only minor, insignificant changes in serum concentrations of clozapine and its metabolites during concomitant treatment with paroxetine [51].

As expected, data from a TDM study indicated that dose-normalized serum concentrations of quetiapine, a CYP3A4 substrate, did not change during coadministration with paroxetine [45].

The possibility of a pharmacokinetic drug interaction between paroxetine and aripiprazole has recently been documented. Fourteen Japanese patients with schizophrenia, treated with aripiprazole (24 mg/day in 5 cases, $12 \mathrm{mg}$ /day in 5 cases, and $6 \mathrm{mg} /$ day in 4 case) for at least 2 weeks, received paroxetine $10 \mathrm{mg} /$ day during the first week and $20 \mathrm{mg}$ /day during the second week [52]. Plasma concentrations of aripiprazole increased significantly $(\mathrm{p}<0.05)$ during coadministration of both paroxetine $10 \mathrm{mg} /$ day (1.5-fold) and paroxetine $20 \mathrm{mg} /$ day (1.7-fold) as compared to baseline, whereas plasma concentrations of its active metabolite, dehydroaripiprazole, were unchanged throughout the study period. Plasma concentrations of the sum of aripiprazole and its active metabolite during coadministration of paroxetine 10 and $20 \mathrm{mg} /$ day were also significantly $(\mathrm{p}<0.05)$ higher $(1.4$-fold and 1.5-fold) than those before paroxetine coadministration. These effects are probably due to the potent inhibitory effect of paroxetine on CYP2D6, the isoform responsible, together with CYP3A4, for aripiprazole biotransformation. Consistent with these findings, in a study of healthy subjects, coadministration of paroxetine $(20 \mathrm{mg} /$ day $)$ decreased systemic clearance of aripiprazole by 58 and 23\% in CYP2D6 EMs and intermediate metabolizers (IMs), respectively, demonstrating that the percentage of inhibition of CYP2D6 activity by coadministration of paroxetine was apparently greater in CYP2D6 EMs than in IMs [53]. 
Iloperidone dose should be reduced by 50\% during coadministration with CYP2D6 inhibitors such as paroxetine $[25,26]$.

\section{Fluvoxamine}

Fluvoxamine influences the activity of various CYP isoenzymes; it is a potent inhibitor of CYP1A2 and CYP2C19 and a moderate inhibitor of CYP2C9 and CYP3A4, while it affects CYP2D6 activity only slightly $[16,36]$. Being an inhibitor of different CYP isoforms, fluvoxamine may impair the elimination of various SGAs.

The pharmacokinetic drug interaction between fluvoxamine and clozapine has been extensively investigated. Formal kinetic studies and case reports have demonstrated that concomitant administration of fluvoxamine (50-100 mg/day) may cause a 5-10-fold increase in plasma concentrations of clozapine, along with signs of toxicity (nausea, dizziness, extrapyramidal symptoms) [51, 54-58]. This drug interaction has been attributed not only to the inhibition of CYP1A2, the major enzyme responsible for clozapine metabolism, but also to the additional inhibitory effects of fluvoxamine on $\mathrm{CYP} 2 \mathrm{C} 19$ and CYP3A4, which also contribute to its biotransformation [59]. Clinicians should be aware of a drug interaction between clozapine and fluvoxamine. Downward dosage adjustments of clozapine may be necessary. However, given the magnitude of this interaction, a pharmacokinetic augmentation strategy has been proposed for the co-administration of fluvoxamine with low doses of clozapine [57, 60-62]. Clinicians using that strategy should use TDM and have a high level of pharmacokinetic expertise.

Several studies have documented that fluvoxamine (50-100 mg/day) may also elevate plasma levels of olanzapine approximately 2-fold, presumably through inhibition of CYP1A2, with possible ADR occurrence [63-66]. The magnitude of the effect of fluvoxamine on plasma levels of olanzapine is lower than observed with clozapine, as olanzapine is metabolized by multiple enzyme systems, namely UGT, whose activity may not be affected by fluvoxamine. The combination of olanzapine and fluvoxamine should be used cautiously and with TDM to avoid olanzapine ADRs (sedation, orthostatic hypotension, tachycardia, transaminase elevations, or seizures). Similar to the fluvoxamine-clozapine combination, a low dose of fluvoxamine $(25 \mathrm{mg} / \mathrm{day})$ has been proposed as an adjunct to reduce olanzapine dose requirements as a cost-saving measure [67].

D'Arrigo et al. [68] evaluated the possibility of a metabolic drug interaction between fluvoxamine and risperidone in schizophrenic patients on a chronic treatment with risperidone, 3-6 $\mathrm{mg} /$ day. While in the 6 patients receiving adjunctive treatment with fluvoxamine $100 \mathrm{mg}$ /day no significant modifications in plasma levels of risperidone and its active metabolite were observed, concentrations increased slightly but significantly (by a mean of $26 \%$ over pretreatment; $p<0.05$ ) in 
the subgroup of 5 subjects treated with a final fluvoxamine dose of $200 \mathrm{mg} / \mathrm{day}$. A dose-dependent inhibitory effect of fluvoxamine on CYP2D6- and/or CYP3A4-mediated 9-hydroxylation of risperidone provides a rational explanation for this drug interaction.

In a large routine TDM program for quetiapine, concomitant administration with fluvoxamine was associated with a significant increase in quetiapine serum concentration-dose $(\mathrm{C} / \mathrm{D})$ ratio $(\mathrm{p}<0.001)$ [45]. This pharmacokinetic drug interaction may be explained by the inhibitory effect of fluvoxamine on the CYP3A4-mediated metabolism of quetiapine.

In an open-label investigation in healthy subjects, coadministration of fluvoxamine (100 $\mathrm{mg} /$ day) resulted in a $40 \%$ decrease in the systemic clearance of a single $3 \mathrm{mg}$ oral dose of aripiprazole, suggesting inhibition of CYP3A4-mediated biotransformation of aripiprazole by fluvoxamine [53].

In healthy volunteers, during combined administration with a single $5 \mathrm{mg}$ sublingual dose of asenapine, a novel antipsychotic partially metabolized by CYP1A2, fluvoxamine $25 \mathrm{mg}$ twice a day resulted in a $29 \%$ increase in asenapine AUC $[25,26]$. The full therapeutic dose of fluvoxamine would be expected to produce a greater increase in plasma asenapine concentrations. Therefore, coadministration of asenapine and fluvoxamine should be approached with caution.

\section{$\underline{\text { Sertraline }}$}

Sertraline is a mild to moderate in vitro inhibitor of CYP2D6 and a weak inhibitor of the other CYP isoenzymes [16, 36].

In an open-label pharmacokinetic investigation involving 11 patients with schizophrenia or schizoaffective disorder stabilized on risperidone therapy (4-6 mg/day), co-medication with sertraline, 50 to $100 \mathrm{mg} /$ day, for 8 weeks did not significantly change steady-state plasma concentrations of risperidone active fraction [69]. However, in the 2 patients receiving the highest dose of sertraline, $150 \mathrm{mg} / \mathrm{day}$, at week 8 total plasma risperidone concentrations were increased by $36 \%$ and $52 \%$ respectively, as compared to baseline values, presumably due to a dose-dependent inhibition of CYP2D6-mediated 9-hydroxylation of risperidone.

Early clinical pharmacokinetic studies documented that sertraline, at dosages $\leq 100 \mathrm{mg} /$ day, did not significantly affect plasma concentrations of clozapine and its major metabolite norclozapine $[38,50]$. On the other hand, two case reports have documented a moderate increase in plasma concentrations of clozapine after coadministration with sertraline at doses of 50 and 300 $\mathrm{mg} /$ day, respectively $[70,71]$.

In a placebo-controlled study in patients with schizophrenia and comorbid major depression, the addition of sertraline, 50 to $100 \mathrm{mg}$ /day, to antipsychotic monotherapy caused minimal but not 
clinically significant changes in serum levels of various SGAs, including risperidone and olanzapine, which were comparable to those observed in placebo-treated patients [72]. In three different TDM studies, concomitant intake of sertraline was found not to affect dose-normalized serum concentrations of olanzapine [63], quetiapine [45], and aripiprazole [46].

\section{Citalopram/Escitalopram}

Citalopram and its active S-enantiomer, escitalopram, are weak in vitro inhibitors of CYP2D6 and are negligible inhibitors of CYP1A2, CYP2C9, CYP2C19 and CYP3A4 [73, 74]. Due to their minimal effect on drug-metabolizing enzymes, citalopram and escitalopram are not expected to cause clinically relevant drug interactions with SGAs.

Concomitant administration of citalopram (20-40 mg/day) was found not to modify steadystate plasma concentrations of clozapine and norclozapine, as reported in two early studies in patients with schizophrenia $[75,76]$. No changes in steady-state plasma concentrations of risperidone and 9-hydroxyrisperidone were observed in 7 patients after administration of citalopram $40 \mathrm{mg} /$ day [76]. By using a mixed model to estimate the effects of comedications on plasma olanzapine concentrations, Botts et al. found that concomitant medication with citalopram did not affect plasma concentrations of olanzapine [77]. In a study from a large routine TDM service, dosecorrected quetiapine serum concentrations were slightly (by 16\%), but significantly $(\mathrm{p}<0.05)$, higher in patients comedicated with citalopram/escitalopram [45]. However, due to the limited increase in quetiapine concentrations and its wide therapeutic index, quetiapine dose adjustment is not considered necessary if citalopram or escitalopram are coadministered. In a routine TDM program for patients treated with aripiprazole, steady-state dose-adjusted serum concentrations of aripiprazole and the sum of aripiprazole and dehydroaripiprazole were approximately $20 \%$ higher $(\mathrm{p}<0.05)$ in patients comedicated with escitalopram $(n=26)$ than in subjects in the monotherapy group ( $\mathrm{n}=60$ ) [46]. The small, though significant, elevation of aripiprazole concentrations may be attributed to the weak inhibitory effect of escitalopram on CYP2D6, which plays a role in the biotransformation of aripiprazole.

\subsubsection{SNRIS}

This section includes venlafaxine, desvenlafaxine, and duloxetine studies. To our knowledge, no study has investigated the effect of levomilnacipran and milnacipran on the SGA pharmacokinetics.

\section{$\underline{\text { Venlafaxine/Desvenlafaxine }}$}


According to in vitro studies, venlafaxine is a weaker CYP2D6 inhibitor than paroxetine, fluoxetine, fluvoxamine and sertraline, and has minimal or no effect on the activity of CYP1A2, CYP2C9 and CYP3A4 [78]. Desvenlafaxine, venlafaxine active metabolite, has no inhibitory effect on the activity of the major CYP isoforms [78].

There is limited data on the effects of venlafaxine and desvenlafaxine on SGA metabolism. In a study of 30 healthy volunteers, treatment with venlafaxine, $150 \mathrm{mg} /$ day for 9 days, caused minimal, presumably not clinically relevant, changes in the pharmacokinetics of a single $1 \mathrm{mg}$ oral dose of risperidone, a CYP2D6 substrate [79]. Plasma concentrations of clozapine were measured in 11 schizophrenic male patients with depressive symptoms who were administered both clozapine and venlafaxine [80]. Low to moderate doses of venlafaxine did not significantly affect plasma clozapine levels. Data from TDM studies documented that concomitant administration with venlafaxine was associated with no changes in dose-normalized serum concentrations of quetiapine [45] nor in those of aripiprazole and its active metabolite dehydroaripiprazole [46].

\section{Duloxetine}

Duloxetine is a moderate inhibitor of CYP2D6, while it has minimal or no effect on the activity of CYP1A2, CYP2C9, CYP2C19, and CYP3A4 [81].

Two open-label prospective trials evaluated the potential drug interaction between duloxetine and SGAs in patients with psychotic disorders [82, 83]. In the first study involving 20

in- or outpatients on antipsychotic medication, the addition of duloxetine (mean final dosage of 83.3 $\pm 26.3 \mathrm{mg}$ /day) over a period of 6 weeks resulted in an increase of dose-corrected serum levels of olanzapine in three patients, while serum levels of clozapine remained substantially unchanged in eleven subjects [82]. In the second trial, administration of duloxetine, $60 \mathrm{mg} / \mathrm{day}$ for up to 6 weeks, to 20 outpatients stabilized on clozapine $(n=6)$, olanzapine $(n=8)$ or risperidone $(n=7)$, did not modify the plasma concentrations of clozapine and olanzapine, which are not CYP2D6 substrates, while it was associated with a modest, but potentially clinically significant, increase in the plasma concentration of the active moiety of risperidone (by a mean 26\%), presumably through inhibition of CYP2D6-mediated 9-hydroxylation of risperidone [83]. On the other hand, in a study based on a TDM database, coadministration of duloxetine, $30-120 \mathrm{mg} /$ day, was not associated with significant effects on the serum concentrations of both risperidone and aripiprazole, another CYP2D6 substrate [84].

\subsubsection{Other newer antidepressants}

\section{$\underline{\text { Reboxetine }}$}


Reboxetine has only weak CYP inhibitory effects [85]. Therefore, reboxetine is not expected to impair SGA elimination. In agreement with this, an open-label pharmacokinetic investigation in 14 patients with schizophrenia or schizoaffective disorder with associated depressive symptoms, documented no effect of a 4 -week adjunctive treatment with reboxetine $8 \mathrm{mg} / \mathrm{day}$ on the plasma concentrations of clozapine $(250-500 \mathrm{mg} /$ day, $\mathrm{n}=7)$, risperidone $(4-6 \mathrm{mg} / \mathrm{day}, \mathrm{n}=7)$ and their main metabolites [86].

\section{Mirtazapine}

According to in vitro studies, mirtazapine has minimal inhibitory effects on the various CYP isoforms and appears to carry a low risk for drug interactions [87]. In a pilot study involving 6 psychiatric patients treated with risperidone (2-6 mg/day), the addition of mirtazapine, $30 \mathrm{mg} / \mathrm{day}$ for 2-4 weeks, did not modify plasma concentrations of risperidone and its active 9-hydroxy metabolite [88]. A subsequent open-label investigation evaluated the effect of mirtazapine, 30 $\mathrm{mg}$ /day for 6 weeks, on steady-state plasma concentrations of various SGAs in 24 patients with chronic schizophrenia [89]. Adjunctive mirtazapine resulted in minimal and statistically insignificant changes in the mean plasma concentrations of clozapine $(200-650 \mathrm{mg} / \mathrm{day}, \mathrm{n}=9)$, risperidone (3-8 mg/day, $\mathrm{n}=8)$, olanzapine $(10-20 \mathrm{mg} /$ day, $\mathrm{n}=7)$, and their major metabolites during the study period, indicating lack of pharmacokinetic drug interaction between mirtazapine and these SGAs. By using data from a routine TDM service, concomitant intake of mirtazapine $(n=12)$ did not significantly affect serum concentrations of aripiprazole or dehydroaripiprazole [46].

\section{Bupropion, agomelatine, vilazodone or vortioxetine}

There is no documentation of pharmacokinetic drug interactions between bupropion, agomelatine, vilazodone or vortioxetine and SGAs. As bupropion is a moderate inhibitor of CYP2D6, it should interfere with the elimination of SGAs partly metabolized by CYP2D6: risperidone, aripiprazole and iloperidone.

\subsubsection{Effect of SGAs on the pharmacokinetics of newer antidepressants}

As SGAs, except for asenapine, do not significantly affect the activity of CYP isoenzymes, they are not expected to impair the elimination of newer antidepressants in usual circumstances [19, $21,25,26]$. On the other hand, any substrate competes with others for the corresponding enzyme and inhibits it; the potency of the inhibition is influenced by substrate affinity and dose. In most clinical situations competitive inhibition is probably irrelevant. In unusual polypharmacy situations, adding a competitive inhibitor (such as SGAs which are not normally considered inhibitors) in a 
patient taking a drug with a narrow therapeutic window may affect another drug's drug metabolism, due to inhibitor accumulation past the tipping point [35].

In a large investigation including two open-label, non-randomized studies in healthy subjects and two placebo-controlled studies in patients with major depressive disorder, adjunctive treatment with aripiprazole caused no meaningful effects on the pharmacokinetics of citalopram, fluoxetine, paroxetine, sertraline or venlafaxine in either healthy subjects or patients [90].

Asenapine is a weak inhibitor of CYP2D6 and should be administered with caution with drugs that are substrates for this isoform. In this respect, coadministration of paroxetine and asenapine has been shown to cause a nearly 2 -fold increase in paroxetine exposure $[25,26]$.

\subsection{Pharmacodynamic interactions}

\subsubsection{Pharmacodynamic drug interactions increasing efficacy}

According to a meta-analysis of adjunctive therapy for depression, aripiprazole, olanzapine (combined with fluoxetine), quetiapine and risperidone showed small to moderately significant effects on clinician-rated depression severity measures when compared to adding placebo with limited benefits but increased ADRs [91]. These positive randomized clinical trials (RCTs) suggest that SGAs may have a synergistic effect and increase the antidepressant response in patients taking antidepressants for major depressive disorder.

There are very few randomized RCTs on psychotic depression [6]. These RCTs suggested a synergistic effect between antipsychotic and antidepressant co-treatment since the combination appeared superior to monotherapy of either drug class. However, most of the RCTs have used TCAs rather than the newer antidepressants; some of them used FGAs. Therefore, there is little information to guide clinicians if they decide to combine newer antidepressants and SGAs for psychotic depression [92].

The idea of combining fluoxetine and olanzapine in pill form would suggest that they have additive or synergistic effects in bipolar depression. A meta-analysis indicates some increase of efficacy, but ADRs were frequent [93].

A SGA meta-analysis of OCD studies suggested some evidence that adding quetiapine or risperidone to antidepressants increases efficacy [94]. Therefore, the limited data from RCTs do not allow commenting on whether SGAs may have additive or synergistic effects on OCD when added to SSRIs. On the other hand, clinical guidelines after lack of response to SSRIs usually recommend SGAs as one of the options.

A meta-analysis indicated that adding newer antidepressants to antipsychotics may reduce negative symptoms [8]. Other articles reviewed proposed that the $\alpha_{2}$ antagonist properties of some 
newer antidepressants such as mirtazapine may explain the improvement of negative symptoms [95].

\subsubsection{Pharmacodynamic drug interactions decreasing efficacy}

There is very limited RCT data on maintenance treatment after bipolar depression [96] but there is general agreement that some antidepressants may increase the switch to mania, whereas bupropion and SSRIs may have fewer risks than TCAs and SNRIs [97]. A meta-analysis suggested that mood stabilizers may not prevent the switch to mania but too few SGA studies have been conducted to establish certainty [98]. Future studies will need to verify whether antidepressants decrease the mood-stabilizing properties of SGAs by increasing mania-switching or not.

\subsubsection{Pharmacodynamic drug interactions increasing safety}

As bupropion treatment can be associated with weight loss, one can propose that adding it to SGAs may decrease the risk of weight gain from SGAs, but there are no related RCTs in PubMed.

Figure 2 indicates that epidemiological studies definitively establish SSRIs as producing a small increased risk for abnormal bleeding by depleting platelets from serotonin, particularly when other risk factors are present. SGAs, particularly clozapine, appear to increase the risk of developing venous thromboembolism by poorly understood mechanisms, including enhancing platelet aggregation [99]. From a pharmacological point of view one could hypothesize that the combination may decrease the risk of SSRI-induced bleeding or clozapine-induced thromboembolism, but we know too little about the pharmacodynamic mechanisms; there is no published data to support this idea.

Reviews of serotonin syndrome [100,101] do not usually list SGAPs as drugs contributing to serotonin syndrome, but the case report literature is much more complicated. Case reports suggest that some SGAs may decrease the risk for serotonin syndrome while other SGAs may increase the risk for serotonin syndrome. In that sense ziprasidone may be a special case, since it can inhibit serotonin reuptake and has been proposed as the single agent causing serotonin syndrome in one case [102] and as a contributing factor in two others [103, 104]. Other cases suggest that withdrawal from olanzapine [105] or clozapine [106] may have contributed to serotonin syndrome. Another case suggested that aripiprazole may have protected against serotonin syndrome [107].

\subsubsection{Pharmacodynamic drug interactions decreasing safety}

Figures 2 and 4 indicate that some newer antidepressants and some SGAs share ADRs but, as far as we know, no studies have been published on the combined increased risk of ADRs, other 
than the previously mentioned study that the olanzapine-fluoxetine combination is associated with substantial risk of ADRs [93].

Pharmacodynamic drug interactions possibly associated with specific newer antidepressant compounds in combination with SGAs may include increased risk for weight gain, sedation, hypertension, decreased seizure threshold, psychotic exacerbation, nausea and anticholinergic ADRs. These possible drug interactions have rarely been studied in the literature, but they can be hypothesized based on pharmacological knowledge. Most SGAs are associated with metabolic ADRs (Figure 4); therefore, mirtazapine (and to a lesser degree paroxetine) probably has an additive risk for metabolic ADRs. Mirtazapine is also likely to increase the risk of sedation in patients taking SGAs.

SNRIs are associated with tachycardia and all except for duloxetine with hypertension. Clozapine is the only SGA that is associated with hypertension (usually $<5 \%$ ). It is likely that the SNRI-clozapine combination may increase the risk for tachycardia and/or hypertension. Most SGAs are associated with increased seizure risk (Figure 4); thus, adding bupropion may further increase that risk.

Bupropion may also exacerbate the risk of psychosis in patients taking SGAs. In smoking cessation trials in schizophrenia, bupropion was used for a short time and did not appear to cause psychotic exacerbations [108]. In a comprehensive review of the use of bupropion in schizophrenia, Englisch et al. described the risk of bupropion-induced psychosis as negligible [109].

Many newer antidepressants are associated with increased risk of nausea and vomiting (Figure 2), which may be important to remember when used in combination with three SGAs associated with nausea: aripiprazole, lurasidone and ziprasidone (Figure 4). Increased risk for antimuscarinic ADRs may occur when combining mirtazapine, paroxetine or reboxetine (Figure 2) with antimuscarinic SGAs: clozapine, olanzapine or high doses of quetiapine (Figure 4).

Less common pharmacodynamic drug interactions possibly associated with combinations between newer antidepressants and SGAs may include increased risk for akathisia, sexual ADRs, long QTc and hepatotoxicity. SSRIs have occasionally been associated with akathisia [110]. Among SGAs, risperidone is particularly prone to cause extrapyramidal symptoms including akathisia, but aripiprazole may be prone to cause more akathisia than other SGAs [111]. It will be interesting to study whether the combination of aripiprazole and akathisia is particularly prone to akathisia or not. In their review, Kumar and Sachdev [112] indicated that some studies suggest that aripiprazole may be particularly more prone to cause akathisia in patients taking antidepressants. It is possible that some SSRIs, due to pharmacodynamic and/or pharmacokinetic drug interactions (e.g., fluoxetine or 
paroxetine are CYP2D6 inhibitors) may contribute to increased akathisia risk in patients taking aripiprazole.

Sexual ADRs are frequent both with newer antidepressants (not all) (Figure 2) and SGAs. The literature does not comment on whether the combination increases the risk or not.

Lethal arrhythmias are very complicated to study since these deaths are relatively rare and are not easily identified in autopsies. Several syndromes are associated with sudden cardiac death. One of them is Brugada syndrome (see footnote 22 of Figure 2) which has been linked with newer antidepressants. Another syndrome associated with sudden cardiac death, long QTc syndrome, is more familiar to psychiatrists and can lead to torsades de pointes. In the 1990s, genetic forms of long QTc syndrome were found to be channelopathies at the cardiac potassium channels. Most clinically relevant drug-related QTc prolongations occur via inhibition of the delayed rectifier potassium current, IKr, a current mediated in humans by the ion channel $\mathrm{KCNH} 2$ encoded by the human ether-a-go-go-related gene (HERG). These prolongations are acquired presentations similar to one of the genetic forms of the disease [113]. Several psychiatric drugs have warnings for QTc prolongation; among SGAs iloperidone and ziprasidone appear much more prone to cause QTc prolongations (Table 4). The FDA has provided a QTc warning regarding the use of high doses of citalopram (Table 4). Most cases of drug-induced torsades de pointes occur in the context of substantial prolongation of the QTc interval, typically to values $>500$ milliseconds, but QTc alone is a relatively poor predictor of arrhythmic risk in any individual patient. Some drugs that substantially prolong the QTc interval produce very low rates of torsades de pointes while others have much smaller QTc effects but are considerably more proarrhythmic [113]. TCAs and some FGAs, particularly phenothiazines, have been clearly associated with torsades de pointes. According to a systematic review of case reports, citalopram, fluoxetine and sertraline may be associated with torsades de pointes [114]. A recent pharmacoepidemiology study suggested that ziprasidone and amisulpride had potential torsadogenic risk similar to haloperidol [115]; a review of case reports proposed that risperidone may rarely cause torsades de pointes [116]. The literature on clinical cases of torsades de pointes is very complex since 1) the cases are frequently associated with polypharmacy and drug interactions, with a pharmacodynamic component involving multiple drugs with HERG channel inhibitory properties and sometimes a pharmacokinetic component, an inhibitor increasing the plasma concentrations of one or several of the drugs [113]; and 2) other risk factors such as geriatric age, female gender, bradycardia, hypokalemia and hypomagnesemia may be important, too [117]. The literature does not discuss the combination of newer antidepressants and SGAs as risk factors for torsades de pointes, but there are two well-controlled SGA studies on QTc incorporating SSRIs in the design $[118,119]$. The addition of paroxetine to iloperidone was 
associated with increased serum iloperidone concentrations and increased QTc; $10 \%$ of the patients had increases $\geq 60 \mathrm{msec}$ but no patient had a QTc $\geq 500 \mathrm{msec}$ [119]. Risperidone with paroxetine and olanzapine with fluvoxamine were associated with mild increases $(<10 \mathrm{msec})$ in QTc [118].

Agomelatine has been definitively associated with liver enzyme elevations. Most cases (90\%) recover after agomelatine discontinuation but severe forms can also occur [120]. Agomelatine should not be combined with clozapine or olanzapine, the two SGAs most frequently associated with liver enzyme elevations. In a recent review of antidepressant-induced liver injury, Voican et al. [121] stated that agomelatine, bupropion and duloxetine are the most frequent of the newer antidepressants that, on rare occasions, can cause life-threatening hepatotoxicity. They suggest that duloxetine should not be administered in those with prior liver problems. Therefore, duloxetine should not be used in those with prior history of liver injury secondary to antipsychotics, or with current liver enzyme elevations during antipsychotic treatment. Figure 4 describes the safest newer antidepressants regarding liver injury.

\section{Conclusion}

Table 4 uses mechanistic pharmacokinetic and pharmacodynamic data which provide a summary of the most important practical drug interaction information for clinicians and recommendations for dealing with drug interactions. The authors would have preferred to use an evidence-based medicine approach in making these recommendations but, unfortunately, most of the pharmacokinetic drug interaction studies were not completed using clinical doses and durations relevant for clinicians. There are almost no pharmacodynamic drug interaction studies; therefore, Table 4 describes pharmacodynamic drug interactions leading to ADRs that can be uncommon or rare. Statistical theory explains that evidence-based medicine approaches focused on average patients cannot rule out rare ADRs in outliers not well represented by the average patient [122] Thus, the idea behind Table 4 is not to convince scientists but to raise clinicians' awareness of drug interaction risks and remind them that both pharmacokinetic and pharmacodynamic drug interactions can contribute to pharmacological actions. The information contained in this article may not fully account for all of the possible drug interaction risks because of the limited studies available; so future updating as new information becomes available will be necessary.

\subsection{Pharmacokinetic drug interactions and clinical implications}

Fluoxetine, fluvoxamine and paroxetine are potent inhibitors that are likely to have clinically relevant effects on several SGA serum levels (Table 4). Adding any of these potent inhibitors to a specific SGA is associated with an increase in SGA serum concentration which may 
be associated with ADRs. The discontinuation of these inhibitors may be associated with a decrease in SGA serum concentration which may be associated with loss of efficacy. On the other hand, if the patient is taking one of these inhibitors and a SGA with potential to be inhibited needs to be added, a lower SGA dose may be advisable. The best way to control for these drug interactions is by checking SGA TDM. When available, as in the cases of clozapine, olanzapine and risperidone, it may be a good idea to consider it. When SGA TDM is not available, Table 4 provides a best estimation of a correction factor based on the limited available literature.

The pharmacokinetic drug interactions associated with the milder inhibitors bupropion, duloxetine or high dosages of sertraline have not been well studied in the literature. Thus, clinicians may need to be watchful when using them with CYP2D6-dependent SGAs: aripiprazole, iloperidone and risperidone (Table 4).

The only SGA that may be relevant as an inhibitor is asenapine, which may be a mild CYP2D6 inhibitor. Consequently, it may present a low drug interaction risk when added to a CYP2D6-dependent antidepressant: paroxetine or venlafaxine.

\subsection{Pharmacodynamic drug interactions and clinical implications}

As described, the literature is very limited in the description of pharmacodynamic drug interactions but in our experience these types of drug interactions are very relevant in clinical practice (Table 4). Section 3.2.1 describes pharmacodynamic drug interactions that can be considered positive: the addition of SGAs to newer antidepressants as adjunctive therapy for major depressive disorder or OCD. These possible additive or synergistic effects are well-known by clinicians and are not described in Table 4.

Table 4 describes some drug interactions with bupropion and mirtazapine that have not been well-studied, but are important for clinicians to have in mind. Clinicians considering an antidepressant in a patient taking clozapine, which has a relatively narrow therapeutic window, may need to check Table 4 before selecting among the newer antidepressants, since some can increase clozapine serum levels, some may increase risk of antimuscarinic ADRs and some may increase the risk of tachycardia and hypertension.

Torsades de pointes is very rare but clinicians adding SSRIs and SGAs may need to remember that checking QTc in an ECG may be helpful; the literature suggests that cases probably result from a combination of multiple factors. Clinicians adding SSRIs and SGAs may want to check for family history of sudden death; personal history of syncopes, arrhythmias or heart conditions; electrolyte disturbances; and co-prescription of other medications that may increase QTc (Table 4). 


\section{Expert opinion}

We have limited understanding of the clinical relevance of drug interactions associated with the inhibitory properties of fluoxetine, fluvoxamine and paroxetine. Unfortunately, the drug interaction studies with SGAs are rather limited. Table 4 provides correction factors based on the limited available literature. These correction factors were calculated using the available pharmacokinetic studies which summarize the data, assuming that the average patient represents the population well; however, there is extensive pharmacokinetic variability between patients, and TDM measurements are advised for optimal titration of the dosage in each individual. The correction factors may not fully account for all of the possible risks of treatment because of the limited studies available; thus, there will be a need to periodically update these correction factors as new knowledge becomes available. In spite of their limitations, these correction factors are useful because: 1) many clinicians have no access to antipsychotic TDM and, as a matter of fact, there is limited clinical data on some SGA TDM (amisulpride, aripiprazole, paliperidone, quetiapine, and ziprasidone) and published TDM data on three compounds (asenapine, iloperidone and lurasidone) is virtually absent; and 2) in our experience, having the correction factor helps clinicians to make decisions. With a correction factor of 5-10, fluvoxamine is a poor antidepressant choice for clozapine patients unless the clinician has access to TDM and sophisticated pharmacokinetic knowledge.

Bupropion and duloxetine are moderate CYP2D6 inhibitors but there are almost no DI studies on SGAPs to verify the clinical relevance of their inhibitory properties for aripiprazole, iloperidone and risperidone. A serious limitation of the SGA drug interaction literature is the lack of studies in clinical samples with high doses of sertraline, which may be a CYP2D6 inhibitor only in high doses. Moreover, in some sensitive patients, high sertraline doses may inhibit other CYPs. The only SGA that may have some likelihood of being a mild inhibitor is asenapine, which has weak CYP2D6 inhibitory properties. Other SGAs and newer antidepressants may be clinically relevant inhibitors in very rare circumstances, but clinicians may need to remember that competitive inhibition is always possible.

It is not easy to conduct drug interaction studies using clinically relevant doses. Pharmaceutical companies tend to invest in simple pharmacokinetic drug interaction studies in volunteers, frequently using single dosing to get approval for the marketing of their drugs, but this type of pharmacokinetic study rarely reflects clinical practice. Drug interaction data in the prescribing information (or package inserts) is usually not designed to provide easy helps for clinicians in correcting pharmacokinetic drug interactions with dose changes. The pharmacokinetic science on newer antidepressants and SGA combinations may be in its adolescence and needing 
maturation, while pharmacodynamic drug interaction science appears to be in its infancy. None of the studies combining newer antidepressants and SGAs for greater efficacy in major depressive disorder or OCD explore whether the combinations are additive or synergistic.

It would be naïve to simply conclude that more studies of newer antidepressant and SGA drug interactions are needed. They are obviously needed, but the lack of funding for clinical research is a major limitation. To progress in this area, collaboration from all interested parties is needed, including: i) drug agencies and pharmaceutical companies; ii) clinicians using newer antidepressant-SGA combinations; iii) researchers with expertise in a) meta-analyses, b) pharmacoepidemiology, c) drug interaction pharmacology; and iv) grant agencies.

The FDA may need to think "out of the box" and look for new ways to encourage pharmaceutical companies possibly interested in marketing new antidepressants and new SGAs for psychotic depression by providing special "incentives", assuming the companies seriously want to study drug interaction issues.

Clinicians frequently co-prescribe newer antidepressants and SGAs. Thousands of US patients take these combinations. There is great need of naturalistic studies describing possible additive or synergistic efficacy and, more importantly, the long-term safety of these combinations. Are early nausea and vomiting more frequent in some of these combinations than in the various monotherapies?

Researchers with expertise in meta-analysis may need to develop better methods to study the safety of newer antidepressant and SGA combinations by comparing ADRs in available SGA RCTs of monotherapy in schizophrenia versus those of adjuvant therapy in major depressive disorder. Researchers with expertise in pharmacoepidemiology need to explore whether rare ADRs such as risk of long QTc may be more frequently associated with SSRI-SGA combinations than with individual drugs. On the other hand, serotonin syndrome may be less frequent in the presence of SGAs (with the probable exception of ziprasidone) and antipsychotic-induced seizures in the presence of SSRIs such as fluoxetine, which may decrease seizure threshold in the average patient. The complexity of pharmacological treatments in the real world cannot be denied since fluoxetine has on rare occasions been associated with seizures.

Researchers with expertise in in vitro drug interaction studies or in vivo clinical studies using isotopes to explore drug clearance need to better study the SGA metabolic pathways and how they change when inhibitors are added, particularly in the complicated conditions used in clinical practices such as adding both an inducer and an inhibitor to an SGA (e.g., adding carbamazepine and fluoxetine to risperidone). 
Grant and health agencies need to remember that pragmatic clinical trials are key in treating complex disorders such as OCD, schizophrenia, psychotic depression and bipolar disorder, where polytherapy is the norm. Pharmaceutical RCTs do not substitute for long-term pragmatic trials that may better inform clinicians of the effectiveness of the various types of mono- and polytherapy frequently used in the real world of clinical practice. Pragmatic trials need to pay better attention to drug interactions.

Progress in the next few years, if this research agenda is followed, should also be accompanied by a better continuous medical education on drug interactions and improvements in psychopharmacology textbooks, so that clinicians begin to pay more attention to pharmacodynamic and pharmacokinetic drug interactions associated with the frequent co-prescription of newer antidepressants and SGAs. Well-educated clinicians will help move the research agenda by publishing drug interaction case reports of unusual combinations and asking for more drug interaction studies from pharmaceutical companies and researchers. 


\section{Bibliography}

1. Stahl SM. Antidepressants. In: Stahl SM, editor. Stahl's Essential Psychopharmacology. 4th ed. Cambridge University Press; New York: 2013. p. 284-369

2. Stahl SM. Antipsychotic agents. In: Stahl SM, editor. Stahl's Essential Psychopharmacology. 4th ed. Cambridge University Press; New York: 2013. p.129-236

3. Maher AR, Maglione M, Bagley S, et al. Efficacy and comparative effectiveness of atypical antipsychotic medications for off-label uses in adults: a systematic review and metaanalysis. JAMA 2011;306:1359-69

4. Schirmbeck F, Esslinger C, Rausch F, et al. Antiserotonergic antipsychotics are associated with obsessive-compulsive symptoms in schizophrenia. Psychol Med 2011; 41: 2361-73

5. Kantrowitz JT, Citrome L. Schizoaffective disorder: a review of current research themes and pharmacological management. CNS Drugs 2011;25:317-31

6. Farahani A, Correll CU. Are antipsychotics or antidepressants needed for psychotic depression? A systematic review and meta-analysis of trials comparing antidepressant or antipsychotic monotherapy with combination treatment. J Clin Psychiatry 2012;73:486-96

- Comprehensive review of treatment for psychotic depression.

7. Rummel C, Kissling W, Leucht S. Antidepressants as add-on treatment to antipsychotics for people with schizophrenia and pronounced negative symptoms: a systematic review of randomized trials. Schizophr Res 2005;80:85-97

8. Singh SP, Singh V, Kar N, Chan K. Efficacy of antidepressants in treating the negative symptoms of chronic schizophrenia: meta-analysis. Br J Psychiatry 2010;197:174-9

9. Bloch $\mathrm{MH}$, Landeros-Weisenberger A, Kelmendi B, et al. A systematic review: antipsychotic augmentation with treatment refractory obsessive-compulsive disorder. Molecular Psychiatry 2006;11:622-32

10. Skapinakis P, Papatheodorou T, Mavreas V. Antipsychotic augmentation of serotonergic antidepressants in treatment-resistant obsessive-compulsive disorder: a metaanalysis of the randomized controlled trials. Eur Neuropsychopharmacol 2007;17:79-93

11. Dold M, Aigner M, Lanzenberger R, Kasper S. Antipsychotic augmentation of serotonin reuptake inhibitors in treatment-resistant obsessive-compulsive disorder: a meta-analysis of double-blind, randomized, placebo-controlled trials. Int J Neuropsychopharmacol $2013 ; 16: 557-574$

- Comprehensive review of treatment augmentation in obsessive-compulsive disorder. 
12. Papakostas GI, Shelton RC, Smith J, Fava M. Augmentation of antidepressants with atypical antipsychotic medications for treatment-resistant major depressive disorder: a metaanalysis. J Clin Psychiatry 2007;68:826-31

13. Shelton RC, Papakostas GI. Augmentation of antidepressants with atypical antipsychotics for treatment-resistant major depressive disorder. Acta Psychiatr Scand 2008;117:253-9

14. Nelson J, Papakostas G. Atypical antipsychotic augmentation in major depressive disorder: a meta-analysis of placebo-controlled randomized trials. Am J Psychiatry 2009;166:980-91

15. Nemeroff CB, Preskorn S, Devane CL. Antidepressant drug-drug interactions: clinical relevance and risk management. CNS Spectr 2007;12(suppl 7):1-13

16. Spina E, Santoro V, D'Arrigo C. Clinically relevant pharmacokinetic drug interactions with second-generation antidepressants: an update. Clin Ther 2008;30:1206-27

- Comprehensive review of newer antidepressant drug interactions.

17. Schellander R, Donnerer J. Antidepressants: clinically relevant drug interactions to be considered. Pharmacology 2010;86:203-15

18. Spina E, Trifirò G, Caraci F. Clinically significant drug interactions with newer antidepressants. CNS Drugs 2012;26:39-67

-. Comprehensive review of the drug interactions of the most recently marketed antidepressants.

19. Spina E, de Leon J. Metabolic drug interactions with newer antipsychotics: a comparative review. Basic \& Clin Pharmacol \& Toxicol 2007;100:4-22

- Comprehensive review of second-generation antipsychotic drug interactions.

20. Conley RR, Kelly DL. Drug-drug interactions associated with second-generation antipsychotics: considerations for clinicians and patients. Psychopharmacol Bull 2007;40:77-97

21. Urichuk L, Prior TI, Dursun S, Baker G. Metabolism of atypical antipsychotics: involvement of cytochrome P450 enzymes and relevance for drug-drug interactions. Curr Drug Metab 2008;9:410-8

22. Kennedy WK, Jann MW, Kutscher EC. Clinically significant drug interactions with atypical antipsychotics. CNS Drugs 2013; 12: 1021-1048

-• Updated review of atypical antipsychotic drug interactions.

23. Spina E. Drug interactions. In: Shorvon S, Perucca E, Engel J, editors. Treatment of Epilepsy, 3rd ed. Wiley-Blackwell Publishing Ltd: Oxford: 2009. p. 361-77 
24. Cozza KL, Armstrong SC, Oesterheld JR. Concise Guide to Drug interaction Principles for Medical Practice: Cytochrome P450s, UGTs, P-Glycoproteins. 2nd ed. American Psychiatric Association: Washington, DC, 2003

25. Tarazi FI, Stahl SM. Iloperidone, asenapine and lurasidone: a primer on their current status. Expert Opin Pharmacother 2012;13:1911-22

26. Bobo VW. Asenapine, iloperidone and lurasidone: critical appraisal of the most recently approved pharmacotherapies for schizophrenia in adults. Expert Rev Clin Pharmacol 2013;6:61-91

27. Lin JH. Transporter-mediated drug interactions. Clinical implications and in vitro assessment. Exp Opin Drug Metab Toxicol 2007;3:81-92

28. O’Brien FE, Dinan TG, Griffin BT, Cryan JF. Interactions between antidepressants and Pglycoprotein at the blood-brain barrier: clinical significance of in vitro and in vivo findings. Br J Pharmacol 2012;165:289-312

29. Moons T, de Roo M, Claes S, Dom G. Relationship between P-glycoprotein and secondgeneration antipsychotics. Pharmacogenomics 2011;12:1193-1211

30. Akamine Y, Yasui-Furukori N, Ieiri I, Uno T. Psychotropic drug-drug interactions involving P-glycoprotein. CNS Drugs 2012;26:959-73

31. Citrome L. Vilazodone for major depressive disorder: a systematic review of the efficacy and safety profile for this newly approved antidepressant - what is the number needed to treat, number needed to harm and likelihood to be helped or harmed? Int $\mathrm{J}$ Clin Pract 2012;66:356-68

32. Gibb A, Deeks ED. Vortioxetine: first global approval. Drugs 2014; 74: 135-45

33. Labbate LA, Fava M, Rosenbaum JF, et al. Handbook of Psychiatric Drug Therapy. Lippincott Williams \& Wilkins: Philadelphia: 2010

34. Pompili M, Serafini G, Innamorati M, et al. Agomelatine, a novel intriguing antidepressant option enhancing neuroplasticity: a critical review. World J Biol Psychiatry 2013;14:412-31

35. de Leon J, Santoro V, D'Arrigo C, Spina E. Interactions between antiepileptics and secondgeneration antipsychotics. Expert Opin Drug Metab Toxicol 2012;8:2-24

-• Updated review of antiepileptic drugs and atypical antipsychotic drug interactions using the same format as this article.

36. Hemeryck A, Belpaire FM. Selective serotonin reuptake inhibitors and cytochrome P-450 mediated drug-drug interactions: an update. Curr Drug Metab 2002;3:13-37 
37. Centorrino F, Baldessarini RJ, Kando J, et al. Serum concentrations of clozapine and its metabolites: Effects of cotreatment with fluoxetine or valproate. Am J Psychiatry $1994 ; 151: 123-5$

38. Centorrino F, Baldessarini RJ, Frankenburg FR, et al. Serum levels of clozapine and norclozapine in patients treated with selective serotonin reuptake inhibitors. Am J Psychiatry 1996;153:820-3

39. Spina E, Avenoso A, Facciolà G, et al. Effect of fluoxetine on the plasma concentrations of clozapine and its major metabolites in patients with schizophrenia. Int Clin Psychopharmacol 1998;13:141-5

40. Diaz FJ, Santoro V, Spina E, et al. Estimating the size of the effects of co-medications on plasma clozapine concentrations using a model that controls for clozapine doses and confounding variables. Pharmacopsychiatry 2008;41:81-91

41. Spina E, Avenoso A, Scordo MG, et al. Inhibition of risperidone metabolism by fluoxetine in patients with schizophrenia : a clinically relevant pharmacokinetic drug interaction. J Clin Psychopharmacol 2002;22:419-23

42. Bondolfi G, Eap CB, Bertschy G, et al. The effect of fluoxetine on the pharmacokinetics and safety of risperidone in psychiatric patients. Pharmacopsychiatry 2002;35:50-6

43. Gossen D, de Suray JM, Vandenhanden F, et al. Influence of fluoxetine on olanzapine pharmacokinetics. AAPS PharmSci 2002;4:1-6

44. Potkin SG, Thyrum PT, Alva G, et al. Effect of fluoxetine and imipramine on the pharmacokinetics and tolerability of the antipsychotic quetiapine. J Clin Psychopharmacol 2002;22:174-82

45. Castberg I, Skogvoll E, Spigset O. Quetiapine and drug interactions: evidence from a routine therapeutic drug monitoring service. J Clin Psychiatry 2007;68:1540-5

46. Waade RB, Christensen H, Rudberg I, et al. Influence of comedication on serum concentrations of aripiprazole and dehydroaripiprazole. Ther Drug Monit 2009;31:233-38

47. Paul S, Cooke BK, Nguyen M. Glossopharyngeal dystonia secondary to a lurasidone fluoxetine CYP-3A4 interaction. Case Rep Psychiatry 2013;Epub 2013 May 16

48. Spina E, Avenoso A, Facciolà G, et al. Plasma concentrations of risperidone and 9hydroxyrisperidone during combined treatment with paroxetine. Ther Drug Monit $2001 ; 23: 223-7$

49. Saito M, Yasui-Furukori N, Nakagami T, et al. Dose-dependent interaction of paroxetine with risperidone in schizophrenic patients. J Clin Psychopharmacol 2005;25:527-32 
50. Spina E, Avenoso A, Salemi M, et al. A. Plasma concentrations of clozapine and its major metabolites during combined treatment with paroxetine or sertraline. Pharmacopsychiatry $2000 ; 33: 213-7$

51. Wetzel H, Anghelescu I, Szegedi A, et al. Pharmacokinetic interactions of clozapine with selective serotonin reuptake inhibitors: differential effects of fluvoxamine and paroxetine in a prospective study. J Clin Psychopharmacol 1998,18:2-9

52. Nemoto K, Mihara K, Nakamura A, et al. Effects of paroxetine on plasma concentrations of aripiprazole and its active metabolite, dehydroaripiprazole, in Japanese patients with schizophrenia. Ther Drug Monit 2012;34:188-92

53. Azuma J, Hasunuma T, Kubo M, et al. The relationship between clinical pharmacokinetics of aripiprazole and CYP2D6 genetic polymorphism: effects of CYP enzyme inhibition by coadministration of paroxetine or fluvoxamine. Eur J Clin Pharmacol 2012;68:29-37

54. Hiemke C, Weighmann H, Hartter S, et al. Elevated serum levels of clozapine after addition of fluvoxamine. J Clin Psychopharmacol 1994;14:279-81

55. Jerling M, Lindstrom L, Bondesson U, Bertilsson L. Fluvoxamine inhibition and carbamazepine induction of the metabolism of clozapine: evidence from a therapeutic drug monitoring service. Ther Drug Monit 1994;16:368-74

56. Kuo FJ, Lane HY, Chang WH. Extrapyramidal symptoms after addition of fluvoxamine to clozapine. J Clin Psychopharmacol 1998;18:483-4

57. Szegedi A, Anghelescu I, Wiesner J, et al. Addition of low-dose of fluvoxamine to low-dose clozapine monotherapy in schizophrenia: drug monitoring and tolerability data from a prospective clinical trial. Pharmacopsychiatry 1999;32:148-53

58. Fabrazzo M, La Pia S, Monteleone P, et al. Fluvoxamine increases plasma and urinary levels of clozapine and its major metabolites in a time- and dose-dependent manner. J Clin Psychopharmacol 2000;20:708-10

59. Olesen OV, Linnet K. Fluvoxamine-clozapine drug interaction: inhibition in vitro of five cytochrome P450 isoforms involved in clozapine metabolism. J Clin Psychopharmacol $2000 ; 20: 35-42$

60. Lammers $\mathrm{CH}$, Deuschle $\mathrm{M}$, Weigmann $\mathrm{H}$, et al. Coadministration of clozapine and fluvoxamine in psychotic patients: clinical experience. Pharmacopsychiatry 1999;2:76-7

61. Lu ML, Lane HY, Chen KP, et al. Fluvoxamine reduces the clozapine dosage needed in refractory schizophrenic patients. J Clin Psychiatry 2000;61:594-9

62. Lu ML, Lane HY, Lin SK, et al. Adjunctive fluvoxamine inhibits clozapine-related weight gain and metabolic disturbances. J Clin Psychiatry 2004;65:766-71 
63. Weigmann H, Gerek S, Zeisig A, et al. Fluvoxamine but not sertraline inhibits the metabolism of olanzapine: evidence from a therapeutic drug monitoring service. Ther Drug Monit 2001;23:410-3

64. de Jong J, Hoogenboom B, van Troostwijk LD, de Haan L. Interaction of olanzapine with fluvoxamine. Psychopharmacology 2001;155:219-20

65. Hiemke C, Avi P, Jabarin M, et al. Fluvoxamine augmentation of olanzapine in chronic schizophrenia: pharmacokinetic interactions and clinical effects. J Clin Psychopharmacol 2002;22:502-6

66. Chiu CC, Lane HY, Huang MC, et al. Dose-dependent alternations in the pharmacokinetics of olanzapine during coadministration of fluvoxamine in patients with schizophrenia. J Clin Pharmacol 2004;44:1385-90

67. Albers LJ, Ozdemir V, Marder SR, et al. Low-dose fluvoxamine as an adjunct to reduce olanzapine therapeutic dose requirements: a prospective dose-adjusted drug interaction strategy. J Clin Psychopharmacol 2005;25:170-4

68. D'Arrigo C, Migliardi G, Santoro V, et al. Effect of fluvoxamine on plasma risperidone concentrations in patients with schizophrenia. Pharmacol Res 2005;52:497-501

69. Spina E, D'Arrigo C, Migliardi G, et al. Plasma risperidone concentrations during combined treatment with sertraline. Ther Drug Monit 2004;26:386-90

70. Chong SA, Tan CH, Lee HS. Worsening of psychosis with clozapine and selective serotonin reuptake inhibitor combination: two case reports. J Clin Psychopharmacol 1997;17:68-9

71. Pinninti NR, de Leon J. Interaction of sertraline with clozapine. J Clin Psychopharmacol $1997 ; 17: 119-20$

72. Pierson K, Addington D, Addington J, Patten S. Serum monitoring of antipsychotic drug levels during concomitant administration of sertraline and antipsychotic medication. Can $\mathrm{J}$ Psychiatry 2006;51:715-8

73. Von Moltke LL, Greenblatt DJ, Grassi JM, et al. Citalopram and desmethylcitalopram in vitro: human cytochromes mediating transformation, and cytochrome inhibitory effects. Biol Psychiatry 1999;46:839-49

74. Von Moltke LL, Greenblatt DJ, Giancarlo GM, et al. Escitalopram (S-citalopram) and its metabolites in vitro: cytochromes mediating biotransformation, inhibitory effects, and comparison to R-citalopram. Drug Metab Dispos 2001;29:1102-9

75. Taylor D, Ellison Z, Ementon Shaw L, et al. Co-administration of citalopram and clozapine: effect on plasma clozapine levels. Int Clin Psychopharmacol 1998;13:19-21 
76. Avenoso A, Facciolà G, Scordo MG, et al. No effect of citalopram on plasma concentrations of clozapine, risperidone and their active metabolites in patients with chronic schizophrenia. Clin Drug Invest 1998;16:393-8

77. Botts S, Diaz FJ, Santoro V, et al. Estimating the effects of co-medications on plasma olanzapine concentrations by using a mixed model. Progr Neuro-Psychopharmacol Biol Psychiatry 2008;32:1453-8

78. Oganesian A, Shilling AD, Young-Sciame R, et al. Desvenlafaxine and venlafaxine exert minimal in vitro inhibition of human cytochrome P450 and P-glycoprotein activities. Psychopharmacol Bull 2009;42:47-63

79. Amchin J, Zarycranski W, Taylor KP, et al. Effect of venlafaxine on the pharmacokinetics of risperidone. J Clin Pharmacol 1999;39:297-309

80. Repo-Tiihonen E, Eloranta A, Hallikainen T, et al. Effects of venlafaxine treatment on clozapine plasma levels in schizophrenic patients. Neuropsychobiology 2005;51:173-6

81. Lobo ED, Bergstrom RF, Reddy S, et al. In vitro and in vivo evaluations of cytochrome P4501A2 interactions with duloxetine. Clin Pharmacokinet 2008;47:191-202

82. Englisch S, Knopf U, Scharnholz B. et al. Duloxetine for major depressive episodes in the course of psychotic disorders: an observational clinical trial. J Psychopharmacol 2009; 23: $875-82$

83. Santoro V, D'Arrigo C, Micò U, et al. Effect of adjunctive duloxetine on the plasma concentrations of clozapine, olanzapine and risperidone in patients with psychotic disorders. J Clin Psychopharmacol 2010;30:634-6

84. Hendset M, Molden E, Enoksen TB, et al. The effect of coadministration of duloxetine on steady-state serum concentration of risperidone and aripiprazole: a study based on therapeutic drug monitoring data. Ther Drug Monit 2010;32:787-90

85. Wienkers LC, Allievi C, Hauer MJ, et al. Cytochrome P-450-mediated metabolism of the individual enantiomers of the antidepressant agent reboxetine in human liver microsomes. Drug Metab Dispos 1999;27:1334-40

86. Spina E, Avenoso A, Scordo MG, et al. No effect of reboxetine on plasma concentrations of clozapine, risperidone and their active metabolites. Ther Drug Monit 2001;23:675-8

87. Stormer E, von Moltke LL, Shader RI, et al. Metabolism of the antidepressant mirtazapine in vitro: contribution of cytochromes P-450 1A2, 2D6, and 3A4. Drug Metab Dispos 2000;28:1168-75 
88. Loonen $\mathrm{AJ}$, Doorschot $\mathrm{CH}$, Oostelbos $\mathrm{MC}$, et al. Lack of drug interaction between mirtazapine and risperidone in psychiatric patients. Eur Neuropsychopharmacol 1999;10:517

89. Zoccali R, Muscatello MR, La Torre D, et al. Lack of pharmacokinetic interaction between mirtazapine and the newer antipsychotics clozapine, risperidone and olanzapine in patients with chronic schizophrenia. Pharmacol Res 2003;48:411-4

90. Boulton DW, Balch AH, Royzman K, et al. The pharmacokinetics of standard antidepressants with aripiprazole as adjunctive therapy: studies in healthy subjects and in patients with major depressive disorder. J Psychopharmacol 2010;24:537-46

91. Spielmans GI, Berman MI, Linardatos E, et al Adjunctive atypical antipsychotic treatment for major depressive disorder: a meta-analysis of depression, quality of life, and safety outcomes. PLoS Med 2013;10:e1001403

92. Rothschild AJ. Challenges in the treatment of major depressive disorder with psychotic features. Schizophr Bull 2013;39:787-96

- Personal review of treatment for psychotic depression by an expert.

93. Silva MT, Zimmermann IR, Galvao TF, et al. Olanzapine plus fluoxetine for bipolar disorder: a systematic review and meta-analysis. J Affect Disord 2013;146:310-8

94. Komossa K, Depping AM, Meyer M, et al. Second generation antipsychotics for obsessive compulsive disorder. Cochrane Database Syst Rev 2010;12:CD008141

95. Hecht EM, Landy DC. Alpha-2 receptor antagonist add-on therapy in the treatment of schizophrenia; a meta-analysis. Schizophr Res 2012;134:202-6

96. Vieta E, Günther O, Locklear J, et al. Effectiveness of psychotropic medications in the maintenance phase of bipolar disorder: a meta-analysis of randomized controlled trials. Int Neuropsychopharmacol 2011;14:1029-49

- Comprehensive review of maintenance treatment in bipolar disorder.

97. Pacchiarotti I, Bond DJ, Baldessarini RJ, et al. The International Society for Bipolar Disorders (ISBD) task force report on antidepressant use in bipolar disorders. Am J Psychiatry 2013;170:1249-62

- Comprehensive review of the controversial use of antidepressants in bipolar disorder.

98. Tondo L, Vázquez G, Baldessarini RJ. Mania associated with antidepressant treatment: comprehensive meta-analytic review. Acta Psychiatr Scand 2010;121:404-14

99. Jönsson AK, Spigset O, Hägg S. Venous thromboembolism in recipients of antipsychotics: incidence, mechanisms and management. CNS Drugs 2012;26:649-62 
100. Isbister GK, Buckley NA, Whyte IM. Serotonin toxicity: a practical approach to diagnosis and treatment. Med J Aust 2007;187:361-5

101. Ables AZ, Nagubilli R. Prevention, recognition, and management of serotonin syndrome. Am Fam Physician 2010;81:1139-42

•- Excellent and practical review on serotonin syndrome.

102. Lin PY, Hong CJ, Tsai SJ. Serotonin syndrome caused by ziprasidone alone. Psychiatry Clin Neurosci 2010;64:338-9

103. Rim CL, Gitlin MJ. Ziprasidone, monoamine oxidase inhibitors, and the serotonin syndrome. J Clin Psychopharmacol 2010;30:470-1

104. El-Okdi NS, Lumbrezer D, Karanovic D, et al. Serotonin syndrome after the use of tramadol and ziprasidone in a patient with a deep brain stimulator for Parkinson disease. Am J Ther 2013 Oct 23. [Epub ahead of print].

105. Himmighoffen H, Seifritz E, Boeker H. Serotonin syndrome after discontinuation of olanzapine in a combined treatment with duloxetine -- case report. Pharmacopsychiatry 2011;44:75-6.

106. Stevenson E, Schembri F, Green DM, et al. Serotonin syndrome associated with clozapine withdrawal. JAMA Neurol 2013;70:1054-5

107. Rittmannsberger H, Werl R. Does aripiprazole protect from serotonin syndrome? Psychiatr Danub 2012;24:100-1

108. Weiner E, Ball MP, Buchholz AS, et al. Bupropion sustained release added to group support for smoking cessation in schizophrenia: a new randomized trial and a meta-analysis. J Clin Psychiatry 2012;73:95-102

109. Englisch S, Morgen K, Meyer-Lindenberg A, Zink M. Risks and benefits of bupropion treatment in schizophrenia: a systematic review of the current literature. Clin Neuropharmacol 2013; 36: :203-15

110. Koliscak LP, Makela EH. Selective serotonin reuptake inhibitor-induced akathisia. J Am Pharm Assoc. 2009;49:e28-36

\section{- Comprehensive review of SSRI-induced akathisia.}

111. Rummel-Kluge C, Komossa K, Schwarz S, et al. Second-generation antipsychotic drugs and extrapyramidal side effects: a systematic review and meta-analysis of head-to-head comparisons. Schizophr Bull 2012;38:167-77

112. Kumar R, Sachdev PS. Akathisia and second-generation antipsychotic drugs. Curr Opin Psychiatry 2009;22:293-9

113. Heist EK, Ruskin JN. Drug-induced arrhythmia. Circulation 2010;122:1426-35 
-. Very thoughtful and clear review of the complex issue of drug-induced arrhythmias to which psychopharmacologists must pay more attention.

114. Kogut C, Breden Crouse E, Vieweg V, et al. Selective serotonin reuptake inhibitors and torsade de pointes: new concepts and new directions derived from a systematic review of cases reports. Ther Adv in Drug Safe 2013;4:189-198

\section{- Good update on SSRI-induced torsades de pointes.}

115. Poluzzi E, Raschi E, Koci A, et al. Antipsychotics and torsadogenic risk: signals emerging from the US FDA Adverse Event Reporting System database. Drug Saf $2013 ; 36: 467-79$

116. Vieweg WV, Hasnain M, Hancox JC, et al. Risperidone, QTc interval prolongation, and torsade de pointes: a systematic review of case reports. Psychopharmacology 2013;228:51524

117. Kannankeril P, Roden DM, Darbar D. Drug-induced long QT syndrome. Pharmacol Rev $2010 ; 62: 760-81$

118. Harrigan EP, Miceli JJ, Anziano R, et al. A randomized evaluation of the effects of six antipsychotic agents on QTc, in the absence and presence of metabolic inhibition. J Clin Psychopharmacol 2004;24:62-9

119. Potkin SG, Preskorn S, Hochfeld M, et al. A thorough QTc study of 3 doses of iloperidone including metabolic inhibition via CYP2D6 and/or CYP3A4 and a comparison to quetiapine and ziprasidone. J Clin Psychopharmacol 2013;33:3-10

120. Gahr M, Freudenmann RW, Connemann BJ, et al. Agomelatine and hepatotoxicity: implications of cumulated data derived from spontaneous reports of adverse drug reactions. Pharmacopsychiatry 2013;46:214-20

121. Voican CS, Corruble E, Naveau S, Perlemuter G. Antidepressant-induced liver injury: a review for clinicians. Am J Psychiatry. 2013 Dec 20. doi: 10.1176/appi.ajp.2013.13050709. [Epub ahead of print].

- Good recent update on the neglected issue of antidepressant-induced liver injury.

122. de Leon J. Evidence-based medicine versus personalized medicine: are they enemies? J Clin Psychopharmacol 2012;32:153-64 
Table 1. Pharmacokinetic parameters of newer antidepressants. Based on Refs. 15, 16, 18 and 32.

\begin{tabular}{|c|c|c|c|c|c|c|}
\hline & $\begin{array}{c}\text { Bioavailability } \\
(\%)\end{array}$ & $\begin{array}{c}\text { Protein binding } \\
(\%)\end{array}$ & $\begin{array}{l}\text { Half-life } \\
\text { (h) }\end{array}$ & Metabolism & Active metabolites & $\begin{array}{l}\text { Inhibitory effect on CYP } \\
\text { isoenzymes }\end{array}$ \\
\hline \multicolumn{7}{|l|}{ SSRI } \\
\hline Citalopram & 95 & 82 & $23-45$ & CYP3A4, CYP2C19, CYP2D6 & & CYP2D6 (weak) \\
\hline Escitalopram & 80 & 56 & 27 & CYP3A4, CYP2C19, CYP2D6 & & CYP2D6 (weak) \\
\hline Fluoxetine & 80 & 95 & 2-4 days & $\begin{array}{l}\text { CYP2D6, CYP2C9, CYP2C19, } \\
\text { CYP3A4 }\end{array}$ & Norfluoxetine & $\begin{array}{l}\text { CYP2D6 (potent) } \\
\text { CYP2C9 (moderate) } \\
\text { CYP2C19 and CYP3A4 } \\
\text { (weak to moderate) } \\
\text { CYP1A2 (weak) }\end{array}$ \\
\hline Fluvoxamine & $<53$ & 77 & $15-22$ & CYP1A2, CYP2D6 & & $\begin{array}{l}\text { CYP1A2 and CYP2C19 } \\
\text { (potent) } \\
\text { CYP2C9 and CYP3A4 } \\
\text { (moderate) } \\
\text { CYP2D6 (weak) }\end{array}$ \\
\hline Paroxetine & $>64$ & 93 & $10-21$ & CYP2D6 (major), CYP3A4 & & $\begin{array}{l}\text { CYP2D6 (potent) } \\
\text { CYP1A2, CYP2C9, } \\
\text { CYP2C19, CYP3A4 (weak) }\end{array}$ \\
\hline Sertraline & $>44$ & 98 & $22-36$ & $\begin{array}{l}\text { CYP2C9, CYP2C19, CYP2D6, } \\
\text { CYP3A4 }\end{array}$ & & $\begin{array}{l}\text { CYP2D6 (weak to } \\
\text { moderate) } \\
\text { CYP1A2, CYP2C9, } \\
\text { CYP2C19 and CYP3A4 } \\
\text { (weak) }\end{array}$ \\
\hline \multicolumn{7}{|l|}{ SNRI } \\
\hline Desvenlafaxine & 80 & 30 & $9-15$ & $\begin{array}{l}\text { UGT, CYP3A4 } \\
\text { Excreted unchanged (45\%) }\end{array}$ & & \\
\hline Duloxetine & 50 & $>90$ & $10-12$ & CYP1A2 (major), CYP2D6 & & CYP2D6 (moderate) \\
\hline Levomilnacipran & 92 & 22 & 12 & $\begin{array}{l}\text { CYP3A4 (18\%), other CYP } \\
\text { and UGTs } \\
\text { Excreted unchanged }(58 \%)\end{array}$ & & \\
\hline Milnacipran & 85 & 13 & $8-10$ & $\begin{array}{l}\text { Glucuronidation }(20-30 \%) \\
\text { CYP3A4 }(10 \%) \\
\text { Excreted unchanged }(50-60 \%)\end{array}$ & & CYP3A4 (weak) \\
\hline
\end{tabular}




\begin{tabular}{|c|c|c|c|c|c|c|}
\hline Venlafaxine & 92 & 27 & 5 & CYP2D6 (major), CYP3A4 & Desvenlafaxine & \\
\hline \multicolumn{7}{|c|}{$\begin{array}{l}\text { Other newer } \\
\text { antidepressants }\end{array}$} \\
\hline Agomelatine & $<5$ & 95 & $1-2$ & CYP1A2 (90\%), CYP2C9 (10\%) & & \\
\hline Bupropion & 90 & 84 & 20 & CYP2B6 & $\begin{array}{l}\text { Hydroxybupropion } \\
\text { Threohydrobupropion } \\
\text { Erythrohydrobupropion }\end{array}$ & CYP2D6 (moderate) \\
\hline Mirtazapine & 50 & 85 & $20-40$ & CYP2D6, CYP3A4, CYP1A2 & & \\
\hline Reboxetine & $>60$ & 97 & $12-16$ & CYP3A4 & & \\
\hline Vilazodone & $72^{\mathrm{a}}$ & 96-99 & $20-24$ & $\begin{array}{l}\text { CYP3A4 (major), CYP2C19, } \\
\text { CYP2D6, Carboxylesterase }\end{array}$ & & CYP2C8 (?) \\
\hline Vortioxetine & 75 & 98 & $57-66$ & $\begin{array}{l}\text { CYP2D6 (major), CYP3A4, } \\
\text { CYP2C19, CYP2C9, CYP2A6, } \\
\text { CYP2C } 8, \text { CYP2B6 }\end{array}$ & & \\
\hline
\end{tabular}

CYP: Cytochrome P450; SNRI: Serotonin and noradrenaline reuptake inhibitor; SSRI: Selective serotonin reuptake inhibitor; UGT: Uridine diphosphate glucuronosyltransferase.

${ }^{\mathrm{a}}$ Decreased absorption when not administered with food. 
Table 2. Pharmacokinetic parameters of second-generation antipsychotics. Based on Refs. 19, 21, 22 and 35.

\begin{tabular}{|c|c|c|c|c|c|}
\hline & $\begin{array}{c}\text { Bioavailability } \\
(\%)\end{array}$ & $\begin{array}{c}\text { Protein } \\
\text { binding }(\%)\end{array}$ & $\begin{array}{l}\text { Half-life } \\
\text { (h) }\end{array}$ & Metabolism & Active metabolites \\
\hline Amisulpride & $43-48$ & 17 & 12 & Unchanged renal excretion & \\
\hline Aripiprazole & 87 & 99 & $48-68$ & CYP2D6, CYP3A4 & Dehydroaripiprazole \\
\hline Asenapine & $35^{\mathrm{a}}$ & 95 & $1-2$ & UGT 1A4, CYP1A2 & \\
\hline Clozapine & $12-81$ & 95 & $6-33$ & $\begin{array}{l}\text { CYP1A2 (major), } \\
\text { CYP2C19, CYP3A4, CYP2D6 }\end{array}$ & Norclozapine $^{1}$ \\
\hline Iloperidone & 96 & 93 & $20-24$ & CYP2D6 (major), CYP3A4 & $\mathrm{P} 88,{ }^{2} \mathrm{P} 95$ \\
\hline Lurasidone & $9-19^{b}$ & 99 & 18 & CYP3A4 & ID-14823 \\
\hline Olanzapine & $60-80$ & 93 & $20-70$ & $\begin{array}{l}\text { CYP1A2 (major), UGT1A4, } \\
\text { CYP2D6, FMO }\end{array}$ & \\
\hline Paliperidone & 28 & 30 & 24 & Minimal hepatic metabolism & \\
\hline Quetiapine & NA & 83 & $5-8$ & CYP3A4 & Norquetiapine \\
\hline Risperidone & 68 & 90 & $3-24$ & CYP2D6 (major), CYP3A4 & 9-hydroxyrisperidone \\
\hline Ziprasidone & $60^{\mathrm{b}}$ & 99 & $4-10$ & CYP3A4, Aldehyde oxidase & \\
\hline
\end{tabular}

CYP: Cytochrome P450; UGT: Uridine diphosphate glucuronosyltransferase.

${ }^{a}$ Asenapine is administered sublingually; drinking or eating $<10$ minutes after administration may decrease absorption.

${ }^{\mathrm{b}}$ Decreased absorption when not administered with food.

${ }^{1}$ Norclozapine does not appear to have antipsychotic efficacy but it may contribute to anticholinergic effects and hypersalivation.

${ }^{2}$ It does not cross the blood-brain barrier. It may contribute to peripheral adverse drug reactions. 
Table 3. Summary of pharmacokinetic drug interactions between newer antidepressants and second-generation antipsychotics.

\begin{tabular}{|c|c|c|c|c|}
\hline Antidepressant & Antipsychotic & Effect & Proposed mechanism & References \\
\hline \multirow[t]{5}{*}{ Fluoxetine } & Clozapine & Increase in plasma clozapine concentrations $(40-70 \%)$ & $\begin{array}{l}\text { Inhibition of various CYP } \\
\text { isoforms (CYP2D6, } \\
\text { CYP2C19 and CYP3A4) }\end{array}$ & $37-40$ \\
\hline & Risperidone & $\begin{array}{l}\text { Increase in plasma concentrations of the active moiety of } \\
\text { risperidone by } 75 \%\end{array}$ & $\begin{array}{l}\text { Inhibition of CYP2D6 } \\
\text { and, to a lesser extent, } \\
\text { CYP3A4 }\end{array}$ & 41,42 \\
\hline & Olanzapine & $\begin{array}{l}\text { No change or minimal increase in plasma olanzapine } \\
\text { concentrations }\end{array}$ & Inhibition of CYP2D6 & 43 \\
\hline & Aripiprazole & Increase by $45 \%$ in plasma concentrations of aripiprazole & $\begin{array}{l}\text { Inhibition of CYP2D6 } \\
\text { and CYP3A4 }\end{array}$ & 46 \\
\hline & Iloperidone & $\begin{array}{l}\text { Increase (up to 2-fold) in plasma iloperidone } \\
\text { concentrations }\end{array}$ & Inhibition of CYP2D6 & 25,26 \\
\hline \multirow[t]{4}{*}{ Paroxetine } & Clozapine & Increase in plasma clozapine concentrations $(20-40 \%)$ & Inhibition of CYP2D6 & $38,50,51$ \\
\hline & Risperidone & $\begin{array}{l}\text { Increase in plasma concentrations of the active moiety of } \\
\text { risperidone by } 40-50 \%\end{array}$ & Inhibition of CYP2D6 & 48,49 \\
\hline & Aripiprazole & $\begin{array}{l}\text { Increase in plasma concentrations of aripiprazole by } 40- \\
50 \%\end{array}$ & Inhibition of CYP2D6 & 52,53 \\
\hline & Iloperidone & $\begin{array}{l}\text { Increase (up to 2-fold) in plasma iloperidone } \\
\text { concentrations }\end{array}$ & Inhibition of CYP2D6 & 25,26 \\
\hline \multirow[t]{6}{*}{ Fluvoxamine } & Clozapine & $\begin{array}{l}\text { Increase (up to 5-10-fold) in plasma clozapine } \\
\text { concentrations }\end{array}$ & $\begin{array}{l}\text { Inhibition of CYP1A2 } \\
\text { and, to a lesser extent, } \\
\text { CYP2C19 and CYP3A4 }\end{array}$ & $51,54-58$ \\
\hline & Olanzapine & Increase (up to 2-fold) in plasma olanzapine concentrations & Inhibition of CYP1A2 & $63-66$ \\
\hline & Risperidone & $\begin{array}{l}\text { No significant changes in plasma risperidone } \\
\text { concentrations at fluvoxamine dosage of } 100 \mathrm{mg} / \mathrm{day} \text {, } \\
\text { increase by } 26 \% \text { at fluvoxamine dose of } 200 \mathrm{mg} / \text { day }\end{array}$ & $\begin{array}{l}\text { Inhibition of CYP2D6 } \\
\text { and CYP3A4 }\end{array}$ & 68 \\
\hline & Quetiapine & Increase in plasma concentrations of quetiapine by $159 \%$ & Inhibition of CYP3A4 & 45 \\
\hline & Aripiprazole & Decrease by $40 \%$ in systemic clearance of aripiprazole & Inhibition of CYP3A4 & 53 \\
\hline & Asenapine & $\begin{array}{l}\text { Increase by } 29 \% \text { in the AUC of asenapine at fluvoxamine } \\
\text { dosage of } 50 \mathrm{mg} / \text { day }\end{array}$ & Inhibition of CYP1A2 & 25,26 \\
\hline
\end{tabular}




\begin{tabular}{|l|l|l|l|c|}
\hline Sertraline & Risperidone & $\begin{array}{l}\text { Increased plasma concentrations of risperidone (36-52\%) only } \\
\text { at high doses of sertraline }(150 \mathrm{mg} / \mathrm{day})\end{array}$ & Inhibition of CYP2D6 & 69 \\
\hline Citalopram/escitalopram & Aripiprazole & $\begin{array}{l}\text { Minimal increase (by 20\%) in plasma concentrations of } \\
\text { aripiprazole and dehydroaripiprazole }\end{array}$ & Inhibition of CYP2D6 & 46 \\
\hline Duloxetine & Risperidone & $\begin{array}{l}\text { Minimal increase (by 26\%) in plasma concentrations of the } \\
\text { active moiety of risperidone }\end{array}$ & Inhibition of CYP2D6 & 83 \\
\hline & Olanzapine & $\begin{array}{l}\text { No change or minimal increase in plasma olanzapine } \\
\text { concentrations }\end{array}$ & Inhibition of CYP2D6 (?) & 82,83 \\
\hline
\end{tabular}

AUC: Area under the curve; CYP: Cytochrome P450. 
Table 4. Practical summary of newer antidepressants and second-generation antipsychotic (SGA) drug interactions

\begin{tabular}{|c|c|c|c|}
\hline ANTIDEPRESSANTS & SGAs & OUTCOME & ACTIONS \\
\hline \multirow[t]{5}{*}{ PK DI. Fluoxetine } & & \multirow{4}{*}{$\begin{array}{l}\uparrow \text { level several wks }{ }^{1} \text { after adding fluoxetine } \\
\downarrow \text { level several wks }{ }^{1} \text { after } \mathrm{D} / \mathrm{C} \text { fluoxetine }\end{array}$} & In the absence of TDM use dose correction factor: ${ }^{2}$ \\
\hline & Aripiprazole, iloperidone, risperidone, & & 0.5 \\
\hline & Clozapine, olanzapine & & 0.75 \\
\hline & Lurasidone, quetiapine & & Unknown in clinical conditions \\
\hline & $\begin{array}{l}\text { Asenapine, amisulpride, paliperidone, } \\
\text { ziprasidone }\end{array}$ & & Possibly no clinically relevant changes \\
\hline \multirow[t]{4}{*}{ PK DI. Paroxetine } & & \multirow{4}{*}{$\begin{array}{l}\uparrow \text { level one wk after adding paroxetine } \\
\downarrow \text { level one wk after D/C paroxetine }\end{array}$} & In the absence of TDM use dose correction factor: ${ }^{2}$ \\
\hline & Aripiprazole, risperidone, iloperidone & & 0.5 \\
\hline & Clozapine & & 0.8 \\
\hline & $\begin{array}{l}\text { Asenapine, amisulpride, lurasidone, } \\
\text { olanzapine paliperidone, quetiapine, } \\
\text { ziprasidone }\end{array}$ & & Possibly no clinically relevant changes \\
\hline \multirow[t]{5}{*}{ PK DI. Fluvoxamine } & & \multirow{4}{*}{$\begin{array}{l}\uparrow \text { level one wk after adding fluvoxamine } \\
\downarrow \text { level one wk after D/C fluvoxamine }\end{array}$} & In the absence of TDM use dose correction factor: ${ }^{2}$ \\
\hline & Clozapine & & 0.1-0.2. Use TDM; varies according to individual \\
\hline & Olanzapine & & 0.5 \\
\hline & $\begin{array}{l}\text { Asenapine, aripiprazole, iloperidone, } \\
\text { lurasidone, quetiapine, risperidone }\end{array}$ & & $\begin{array}{l}\text { Caution (not well studied, current approximation } \\
0.5-0.75 \text { ) }\end{array}$ \\
\hline & $\begin{array}{l}\text { Amisulpride, paliperidone, } \\
\text { ziprasidone }\end{array}$ & & Possibly no clinically relevant changes \\
\hline \multirow[t]{2}{*}{$\begin{array}{l}\text { PK DI. Sertraline. It may be } \\
\text { relevant only in high doses }\end{array}$} & $\begin{array}{l}\text { Aripiprazole, clozapine, iloperidone, } \\
\text { risperidone }\end{array}$ & $\begin{array}{l}\uparrow \text { level one wk after adding sertraline } \\
\downarrow \text { level one wk after } D / C \text { sertraline }\end{array}$ & $\begin{array}{l}\text { A. Be aware } \\
\text { B. Monitor for ADRs (after adding) and lack of } \\
\text { efficacy (after D/C) } \\
\text { C. Consider TDM }\end{array}$ \\
\hline & $\begin{array}{l}\text { Asenapine, amisulpride, lurasidone, } \\
\text { olanzapine paliperidone, quetiapine, } \\
\text { ziprasidone }\end{array}$ & & Possibly no clinically relevant changes \\
\hline \multirow[t]{2}{*}{$\begin{array}{l}\text { PD DI. Bupropion and } \\
\text { duloxetine }\end{array}$} & Aripiprazole, risperidone, iloperidone & $\begin{array}{l}\uparrow \text { level one wk after adding bupropion or } \\
\text { duloxetine } \\
\downarrow \text { level one wk after D/C bupropion or } \\
\text { duloxetine }\end{array}$ & $\begin{array}{l}\text { A. Be aware } \\
\text { B. Monitor for ADRs (after adding) and lack of } \\
\text { efficacy (after D/C) } \\
\text { C. Consider TDM }\end{array}$ \\
\hline & $\begin{array}{l}\text { Asenapine, amisulpride, clozapine, } \\
\text { lurasidone, olanzapine paliperidone, } \\
\text { quetiapine ziprasidone }\end{array}$ & & Possibly no clinically relevant changes \\
\hline PK DI. Asenapine & Paroxetine, venlafaxine & $\begin{array}{l}\uparrow \text { level one wk after adding asenapine } \\
\downarrow \text { level one wk after D/C asenapine }\end{array}$ & $\begin{array}{l}\text { A. Be aware } \\
\text { B. Monitor for ADRs (after adding) and lack of } \\
\text { efficacy (after } \mathrm{D} / \mathrm{C} \text { ) }\end{array}$ \\
\hline PD DI. Bupropion & All SGAs & Weight loss & Be aware \\
\hline
\end{tabular}




\begin{tabular}{|c|c|c|c|}
\hline PD DI. Bupropion & $\begin{array}{l}\text { All SGAs (clozapine }>\text { olanzapine, } \\
\text { quetiapine }>\text { other) }\end{array}$ & $\uparrow$ risk for seizures & Be aware \\
\hline PD DI. Bupropion & All SGAs when used in psychosis & May rarely cause psychotic exacerbations & Be aware \\
\hline PD DI. Mirtazapine & All SGAs & $\begin{array}{l}\text { Weight gain and increased metabolic ADRs } \\
\uparrow \text { sedation risk from most SGAs }\end{array}$ & $\begin{array}{l}\text { A. Be aware } \\
\text { B. Monitor for ADRs }\end{array}$ \\
\hline $\begin{array}{l}\text { PD DI. Mirtazapine, } \\
\text { paroxetine and reboxetine }\end{array}$ & $\begin{array}{l}\text { Clozapine, olanzapine, high quetiapine } \\
\text { doses }\end{array}$ & $\uparrow$ risk for antimuscarinic ADRs & $\begin{array}{l}\text { A. Be aware } \\
\text { B. Monitor for ADRs }\end{array}$ \\
\hline $\begin{array}{l}\text { PD DI. Desvenlafaxine, } \\
\text { duloxetine, levominalcipran, } \\
\text { milnacipran and venlafaxine }\end{array}$ & Clozapine & $\uparrow$ risk for tachycardia and/or hypertension & $\begin{array}{l}\text { A. Be aware } \\
\text { B. Monitor for ADRs }\end{array}$ \\
\hline $\begin{array}{l}\text { PD DI. Most newer } \\
\text { antidepressants }\end{array}$ & Aripiprazole, lurasidone, ziprasidone & $\begin{array}{l}\text { Possible additive risk for nausea and } \\
\text { vomiting }\end{array}$ & Monitor closely \\
\hline PD DI. SSRIs & SGAs & Possible additive risk for $\uparrow$ QTc & $\begin{array}{l}\text { A. Be vigilant (can be lethal) } \\
\text { B. Consider need for ECG } \\
\text { C. Torsades de pointes is very rare but additive risk } \\
\text { factors are family history of sudden death; personal } \\
\text { history of syncopes, arrhythmias or heart cond- } \\
\text { itions; hypokalemia, hypomagnesemia, and co- } \\
\text { prescription of other medications that } \uparrow \text { QTc. Cases } \\
\text { are more frequent in females aged }>65 \text { years. } \\
\text { D. In the US, consider legal risk. Some SGAPs } \\
\text { (iloperidone and ziprasidone) have been approved } \\
\text { with warnings after particular concern for QTc } \\
\text { prolongation and FDA asked for more studies. The } \\
\text { FDA requires a QTc warning for the use of high } \\
\text { doses of citalopram. Consider these warnings when } \\
\text { co-prescribing. }\end{array}$ \\
\hline
\end{tabular}

\section{ADR: Adverse drug reaction; D/C: Discontinuing; FDA: Food and Drug Administration; PD DI: Pharmacodynamic drug interaction; PK DI:}

Pharmacokinetic drug interaction; SGA: Second-generation antipsychotic; SNRI: Serotonin and noradrenaline reuptake inhibitor; SSRI: Selective serotonin reuptake inhibitor.

${ }^{1}$ Norfluoxetine, fluoxetine's main metabolite, is a more powerful inhibitor than fluoxetine and has a very long half-life. Reaching norfluoxetine steady-state in an average subject may take up to 2-3 months, and 6 months in a non-average patient.

${ }^{2} \mathrm{~A}$ correction factor is used to modify dosing to account for DI. For example, a correction factor of 0.5 indicates that the substrate dose should be halved. The recommendations are based on the limited information available.

${ }^{3}$ Drugs preceding " $>$ " will produce a more powerful outcome than the drugs listed after ">". 


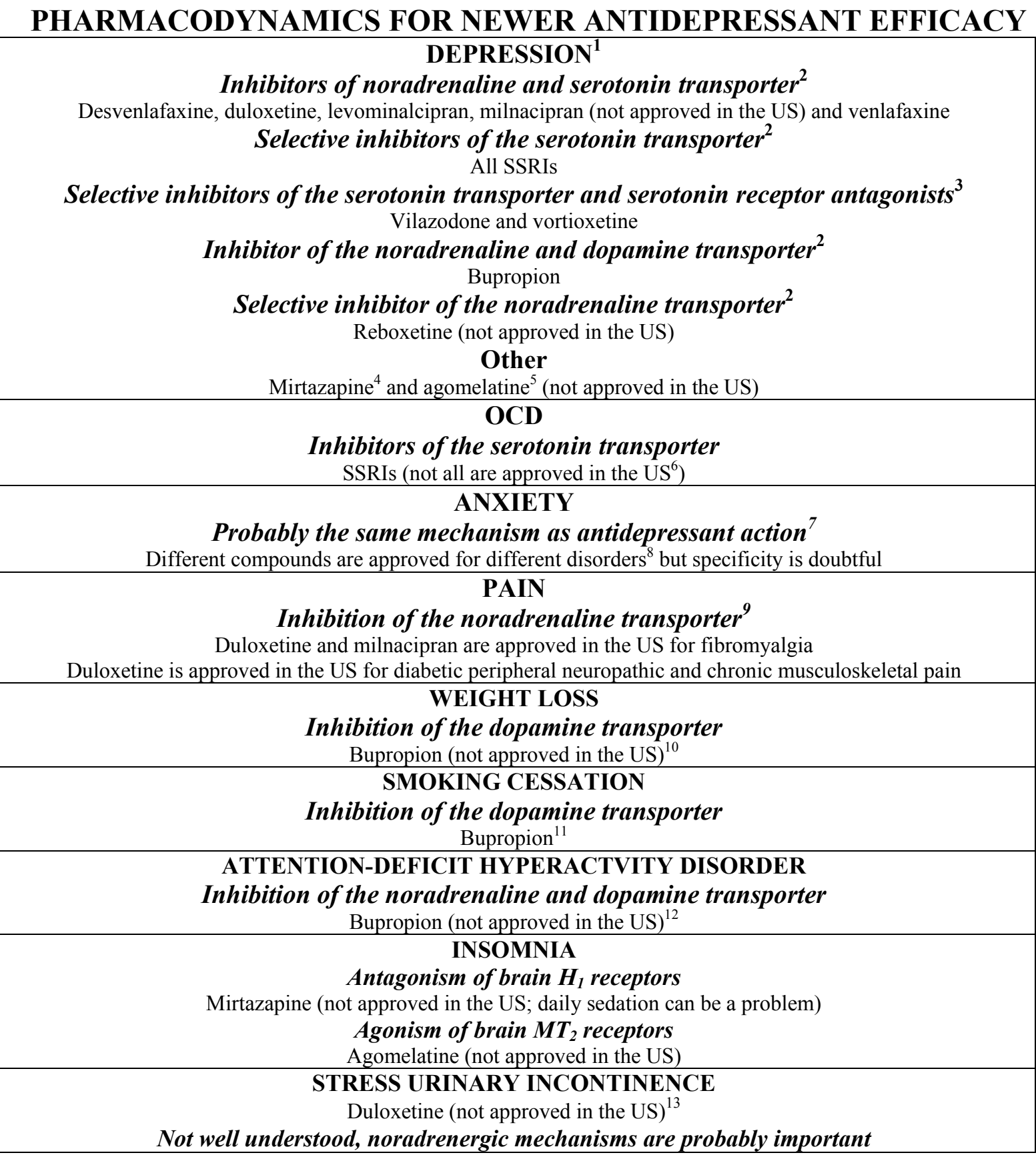

Figure 1. Pharmacodynamics of efficacy for newer antidepressants

5-HT: Serotonin receptor; $\alpha$ : Alpha adrenergic receptor; H: Histamine receptor; MT: Melatonin receptors; OCD: Obsessive-compulsive disorder; RCT: Randomized clinical trial; SSRI: Selective serotonin reuptake inhibitor. References were excluded to reduce the total number of references. The second author can provide them to interested readers.

${ }^{1}$ Different meta-analyses have proposed that 1) escitalopram, mirtazapine, sertraline and venlafaxine may be more efficacious and that escitalopram and sertraline have the best profiles for efficacy and acceptability; 2) current evidence does not warrant recommending a particular newer antidepressant; 3) duloxetine and venlafaxine may have superior efficacy to SSRIs, which milnacipran may not have; 4) escitalopram may the most effective and cost-effective in primary care; 5) reboxetine may be less efficacious than other newer antidepressants; and 6) agomelatine may not be superior to placebo. 
${ }^{2}$ Textbooks usually state that most new antidepressants act by inhibiting reuptake transporters.

${ }^{3}$ Vilazadone is described as a dual-acting serotonergic antidepressant that combines selective 5 -HT reuptake inhibition with partial agonism of the 5- $\mathrm{HT}_{1 \mathrm{~A}}$ receptor. Vortioxetine is decribed as combining 5-HT reuptake inhibition with 5- $\mathrm{HT}_{3 \mathrm{~A}}$ and 5- $\mathrm{HT}_{7}$ receptor antagonism, 5-HT $1 \mathrm{~B}$ receptor partial agonism, 5- $\mathrm{HT}_{1 \mathrm{~A}}$ receptor agonism.

${ }^{4}$ Different textbooks list different mechanisms of action for mirtazapine. Labbate et al. [33] list mirtazapine as an $\alpha_{2}$ adrenergic receptor antagonist but also recognized that it has 5- $\mathrm{HT}_{2 \mathrm{~A}}$ and 5$\mathrm{HT}_{2 \mathrm{C}}$ antagonist properties. Other articles and/or textbooks endorse other variants of this theory.

${ }^{5}$ Agomelatine is a melatonergic analogue drug acting as a $\mathrm{MT}_{1} / \mathrm{MT}_{2}$ agonist and a $5-\mathrm{HT}_{2 \mathrm{C}}$ antagonist.

${ }^{6}$ Fluoxetine, fluvoxamine, paroxetine and sertraline are approved in the US for OCD. Antidepressants with dual action such as duloxetine, desvenlafaxine and venlafaxine are used offlabel.Vortioxetine has had inconsistent results in generalized anxiety disorder RCTs.

${ }^{7}$ There are few attempts to describe the antidepressant pharmacological mechanism in anxiety disorders; the literature usually assumes that the various antidepressants work in anxiety using the same mechanism as in depression.

${ }^{8}$ Duloxetine, escitalopram, paroxetine, and venlafaxine are approved for generalized anxiety in the US. Paroxetine, sertraline and venlafaxine are approved for social anxiety in the US. Paroxetine, sertraline and venlafaxine are approved for panic disorders in the US. A meta-analysis described the following antidepressants as significantly superior to placebo for panic disorder patients with the following increasing order of effectiveness: citalopram, sertraline, paroxetine, fluoxetine, and venlafaxine for panic symptoms and paroxetine, fluoxetine, fluvoxamine, citalopram, venlafaxine, and mirtazapine for overall anxiety symptoms. Aside from reboxetine and fluvoxamine, all drugs were associated with significantly lower dropout rates as compared with placebo. Based on a few agomelatine RCTs and uncontrolled studies, agomelatonine was considered a promising option when other pharmacological treatments had failed in anxiety disorders.

${ }^{9}$ It is believed that for pain treatment the inhibition of the norepinephrine transporter may be more important than the inhibition of the serotonin transporter. A review included all antidepressant RCTs in pain syndromes including fibromyalgia, painful diabetic neuropathy, postherpetic neuralgia, and neuropathic pain (or painful neuropathy). Although venlafaxine is not approved in the US for pain, some RCTs support its use. The benefits of duloxetine and milnacipran over placebo in fibromyalgia are small.

${ }^{10} \mathrm{~A}$ meta-analysis indicated that weight loss with fluoxetine appears to be limited to the acute phase of treatment. The combinations bupropion-zonisamide and bupropion-naltrexone are being studied in RCTs for weight loss.

${ }^{11}$ Bupropion is approved for smoking cessation in the US.

${ }^{12}$ According to a meta-analysis, bupropion is superior to placebo and effective in adults. However, its acceptability and tolerability were not significantly higher than those of placebo. There is very limited data on other antidepressants.

${ }^{13}$ Duloxetine can significantly improve the quality of life of patients with stress urinary incontinence, but it is unclear whether or not benefits are sustainable. 


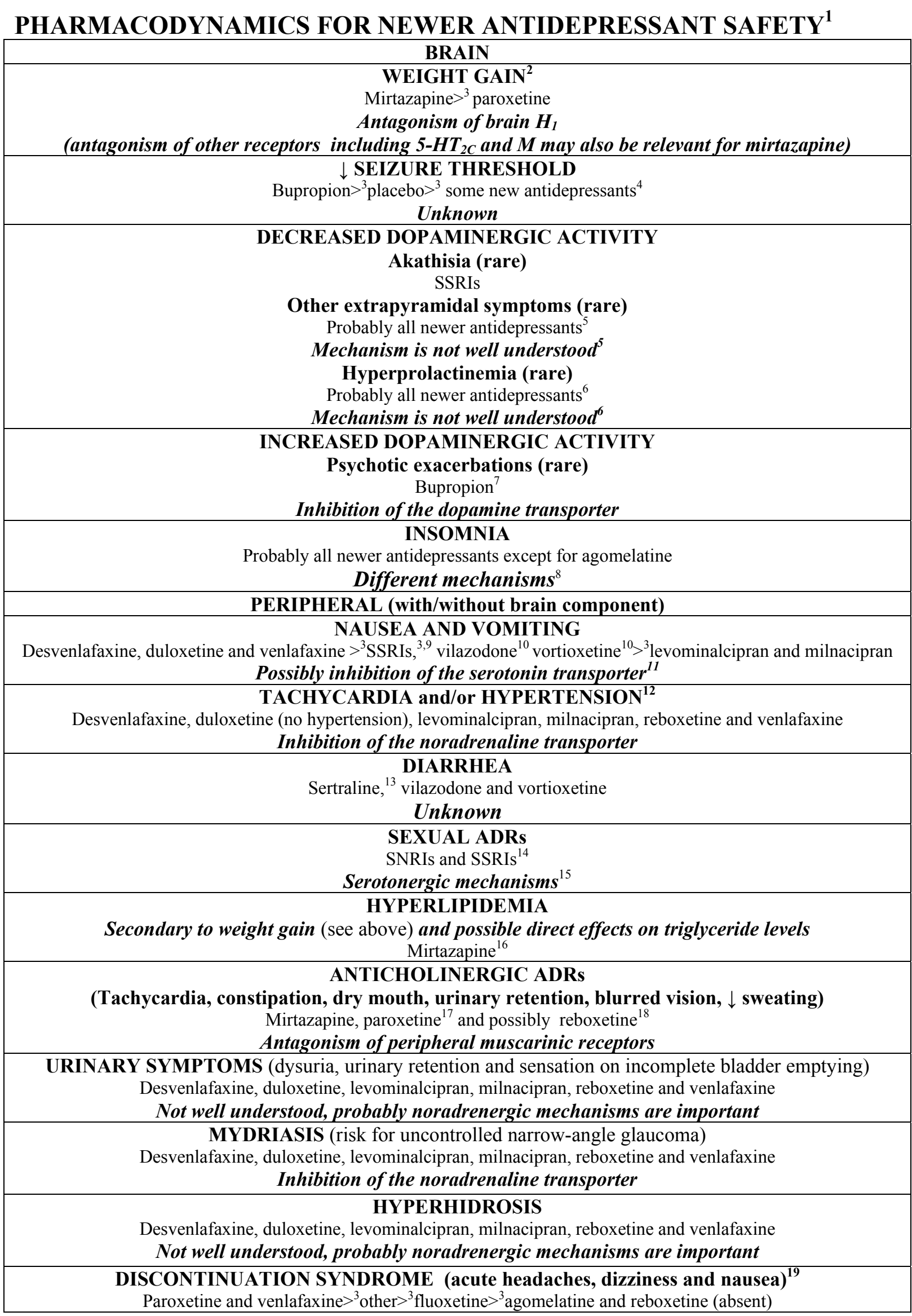




\begin{tabular}{|c|}
\hline Not well understood ${ }^{19}$ \\
\hline $\begin{array}{l}\text { RISK FOR BLEEDING (rare but potentially lethal): } \\
\text { SSRIs usually combined with other drugs with hemorrhagic risk or delivery or surgery } \\
\text { Serotonin depletion in platelets due to inhibition of serotonin transporter and other mechanisms } \text { se }^{20}\end{array}$ \\
\hline $\begin{array}{l}\text { SEROTONIN SYNDROME (very rare but potentially lethal) } \\
\text { Usually require combinations of several drugs increasing serotonin activity } \\
\text { Increased serotonin activity in brain and periphery }\end{array}$ \\
\hline $\begin{array}{l}\text { SUDDEN CARDIAC DEATH ASSOCIATED WITH ARRYTHMIAS (very rare) } \\
\text { Torsades de pointes } \\
\text { Citalopram, fluoxetine, sertraline }{ }^{21} \\
\text { Antagonism of heart repolarizing potassium channels } \\
\text { Risk for patients with Brugada syndrome } \text { s. }^{22} \\
\text { Fluoxetine, fluvoxamine and paroxetine }{ }^{23} \\
\text { Antagonism of heart sodium, potassium or calcium channel }\end{array}$ \\
\hline $\begin{array}{c}\text { NEUTROPENIA (rare) } \\
\text { Mirtazapine } \\
\text { Unknown }\end{array}$ \\
\hline $\begin{array}{c}\text { HYPONATREMIA (rare, more frequent in geriatric females) } \\
\text { Probably all newer antidepressants } \\
\text { SIADH }{ }^{24}\end{array}$ \\
\hline $\begin{array}{c}\text { LIVER INJURY } \\
\text { Live enzyme elevations } \\
\text { Agomelatine (up to } 5 \% \text { in } 50 \mathrm{mg} / \text { day) }>^{3} \text { probably rare in all other newer antidepressants } \\
\text { Unknown } \\
\text { Life-threatening liver-injury } \\
\text { Agomelatine, bupropion and duloxetine }>^{3} \text { other }>^{3} \text { citalopram, escitalopram, paroxetine and fluvoxamine } \\
\text { Poorly understood and considered idiosyncratic (immune-allergic or metabolic) }\end{array}$ \\
\hline
\end{tabular}

Figure 2. Pharmacodynamics of safety for newer antidepressants.

5-HT: Serotonin receptor; ADR: Adverse drug reaction; ECG: Electrocardiogram; H: Histamine receptor; M: Muscarinic receptor; TCA: Tricyclic antidepressant; RCT: Randomized clinical trial; SIADH: Syndrome of inappropriate antidiuretic hormone; SNRI: Serotonin and noradrenaline reuptake inhibitor; SSRI: Selective serotonin reuptake inhibitor. References were excluded to reduce the total number of references. The second author can provide them to interested readers.

${ }^{1}$ The more comprehensive review comparing new antidepressant safety did not include more recently marketed compounds.

${ }^{2}$ Agomelatine is a 5-HT2 ${ }_{\mathrm{C}}$ antagonist. Insufficient data is available on long-term treatment to rule it out as a cause of weight gain. Case reports indicated some patients may gain significant weight with agomelatine long-term treatment.

${ }^{3}$ Drugs preceding ">" will produce this ADR more frequently than drugs following ">".

${ }^{4} \mathrm{~A}$ comprehensive literature review described bupropion as the only newer antidepressant associated with increased seizure risk in RCTs. As a matter of fact, when other newer antidepressants (including citalopram, duloxetine, escitalopram, fluoxetine, mirtazapine, paroxetine, sertraline, and venlafaxine) were combined, they appear to have less risk than placebo. Moreover, animal studies, particularly of fluoxetine, suggest that it may have anti-seizure activity. In case reports, newer antidepressants other than bupropion have occasionally been associated with seizures.

${ }^{5}$ Extrapyramidal symptoms have been reported with different classes of antidepressants, are not dose-related, and can develop with short-term or long-term use.

${ }^{6}$ Symptomatic hyperprolactinemia has been reported with nearly all antidepressants. Incidence rates are not clearly established and symptoms were very rare. The mechanism by which antidepressants may cause hyperprolactinemia is not fully understood, though several theories have been postulated, such as serotonin stimulation of GABAergic neurons and indirect modulation of prolactin release by serotonin. 
${ }^{7}$ The literature is somewhat contradictory but, in selected cases, bupropion appears to be associated with the induction of psychotic symptoms in addition to the precipitation or worsening of an existing psychotic syndrome.

${ }^{8}$ Proposed mechanisms: 1) SSRIs may cause insomnia by $5-\mathrm{HT}_{2}$ stimulation; 2) SNRIs and reboxetine may cause insomnia by blocking the noradrenaline transporter; and 3) mirtazapine may have a reverse-dose response effect with sedation a lower doses and with insomnia at higher doses. $\mathrm{H}_{1}$ antagonism is predominant at lower doses, while increased noradrenerigic activity is predominant at higher doses.

${ }^{9}$ Nausea and vomiting are the most frequent causes of discontinuation of newer antidepressants during the first 30 days of treatment. They are $10 \%$ more frequent in venlafaxine than in SSRIs.

${ }^{10}$ There are no comparisons of vilazodone and vortioxetine with other newer antidepressants. The estimate of the frequency of nausea is a rough estimate based on placebo-controlled RCTs.

${ }^{11}$ Possibly explained by inhibition of the serotonin transporter.

${ }^{12}$ In a comprehensive review comparing newer antidepressant safety, venlafaxine was significantly associated with hypertension when compared with other newer antidepressants. Desvenlafaxine and milnacipran also appear to cause hypertension. Duloxetine has not been consistently associated with hypertension; increases in blood pressure have been mild, but caution should be used in patients with hypertension.

${ }^{13}$ Comprehensive reviews and meta-analyses agree that sertraline is associated with more diarrhea risk than other newer antidepressants. The literature does not provide a mechanistic explanation for this increased risk.

${ }^{14}$ Bupropion and mirtazapine may not be different than placebo. Agomelatine and reboxetine are probably associated with very low risk for sexual ADRs. Vilazodone appears to have low risk for sexual ADRs but is associated with more sexual ADRs than placebo.

${ }^{15}$ It has been proposed that sexual ADRS may be related to serotonergic stimulation of 5- $\mathrm{HT}_{2}$ and 5$\mathrm{HT}_{3}$ receptors but has a complex origin probably also involving the effect of 5-HT on nitric oxide production as well as other systems.

${ }^{16}$ Mirtazepine may increase triglyceride levels but this has not been well studied.

${ }^{17}$ Mirtazepine and paroxetine have low antimuscarinic activity. There is some data that citalopram, escitalopram, fluoxetine and sertraline may have potential to show antimuscarinic activity in some circumstances.

${ }^{18}$ Reboxetine frequently causes dry mouth and constipation, and more rarely urinary retention. It has been proposed that the noradrenergic mechanism may explain these antimuscarinic symptoms because 1) reboxetine's affinity for muscarinic receptors is too low to be relevant at therapeutic doses, and 2) no metabolites with greater antimuscarinic activity have been identified.

${ }^{19}$ SSRI discontinuation included somatic symptoms such as dizziness, lethargy, and sleep disturbances, as well as psychological symptoms such as anxiety/agitation, irritability, and poor concentration. The literature provides very limited information on possible mechanisms.

${ }^{20}$ It has been proposed that an SSRI-induced increase in gastric acid secretion may explain the gastrointestinal bleeding risk and that SSRI-related effects on platelet reactivity, endothelial reactivity, and inflammatory markers may explain the protective effect against ischemic heart disease.

${ }^{21} \mathrm{~A}$ comprehensive literature review indicated that citalopram (8 cases), fluoxetine (6 cases) and sertraline (1 case) can rarely be associated with torsade de pointes.

${ }^{22}$ Brugada syndrome is identified by a specific ECG pattern (pseudo right bundle branch block and persistent ST elevation in leads V1 to V3) and high incidence of ventricular fibrillation in the absence of structural heart disease. Brugada syndrome is a channelopathy explained by genetic abnormalities in the cardiac sodium, potassium or calcium channels.

${ }^{23}$ Fluoxetine, fluvoxamine, and paroxetine should preferably be avoided. 
${ }^{24}$ All newer antidepressants are probably able to cause hyponatremia on rare occasions. It usually happens in geriatric patients, particularly females. The literature usually describes these cases as SIADH but it is not clear why antidepressants can cause SIADH. 
PHARMACODYNAMICS FOR SGA EFFICACY

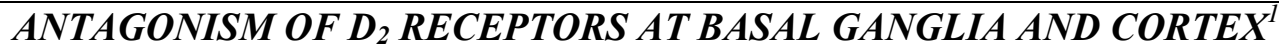

Explains antipsychotic efficacy in schizophrenia

All SGAs are approved in the US except amisulpride ${ }^{2}$

Explains antipsychotic efficacy in other psychoses

None are approved in the US ${ }^{3}$

Possibly explains anti-manic properties

Aripiprazole, asenapine, olanzapine, quetiapine, risperidone and ziprasidone are approved in the US as montherapy ${ }^{4}$

Possibly explains postulated mood-stabilizing properties (maintenance in bipolar disorder)

Aripiprazole and olanzapine are approved in the US as monotherapy

Possibly explains anti-irritability action in autism

Aripiprazole and risperidone are approved in the US

Possibly explains postulated anti-OCD properties when added to serotonergic antidepressants

None are approved in the US but reasonable data exist on risperidone and quetiapine

DEPRESSION

Treatment of bipolar depression

Lurasidone and quetiapine are approved in the US as monotherapy ${ }^{6}$

Adjunctive therapy of treatment-resistant depression

Aripiprazole, quetiapine, olanzapine are approved in the $\mathrm{US}^{7}$

Different theories on mechanism of action ${ }^{8}$

Figure 3. Pharmacodynamics of efficacy for SGAs

5-HT: Serotonin receptor; $\alpha$ : Alpha adrenergic receptor; AP: Antipsychotic; D: Dopamine receptor; OCD: Obsessive-compulsive disorder; RCT: Randomized clinical trial; SGA: Second-generation antipsychotic. This figure is an update from Figure 4 in a prior article [35]. References were excluded to reduce the total number of references. The second author can provide them to interested readers.

${ }^{1}$ All APs are $\mathrm{D}_{2}$ antagonists except aripiprazole, which is a partial agonist (some authors have proposed that occasionally aripiprazole can be associated with worsening of psychosis). Brain imaging studies indicate that antipsychotic efficacy may be associated with $\mathrm{D}_{2}$ antagonism at the basal ganglia and cortex.

${ }^{2}$ Amisulpride is approved in Europe but has not been studied for approval in the US.

${ }^{3}$ No SGA is approved for psychosis (or behaviors) in dementing illnesses. Paliperidone is approved for schizoaffective disorder in the US.

${ }^{4}$ Aripiprazole, asenapine, quetiapine, risperidone, and olanzapine have been approved for adjunctive therapy with lithium or valproate. Other SGAs have not been studied in RCTs.

${ }^{5}$ Quetiapine has been approved for adjunctive therapy with lithium or valproate.

${ }^{6}$ Lurasidone has been approved for adjunctive therapy with lithium or valproate.

${ }^{7}$ Olanzapine is approved in combination with fluoxetine. Risperidone had some positive results in RCTs.

${ }^{8}$ The mechanisms proposed in bipolar depression include: i) a high ratio between $5-\mathrm{HT}_{2 \mathrm{~A}} / \mathrm{D}_{2}$ receptors, and ii) a possible role for $5-\mathrm{HT}_{2 \mathrm{~A}}$ or $\alpha_{2}$ antagonism. A mechanism proposed for adjunctive treatment in major depressive disorder is a $5-\mathrm{HT}_{2 \mathrm{~A}}$ antagonism that may be shared by approved SGAs. Specific compound mechanisms include: i) 5-HT $\mathrm{HA}_{1 \mathrm{~A}}$ partial agonism only for aripiprazole and norquetiapine, the main active metabolite of quetiapine; ii) $5-\mathrm{HT} 2 \mathrm{C}$ antagonism and inhibition of the noradrenaline transporter by norquetiapine, and iii) antagonism at presynaptic $\alpha 2,5$-HT2C, and 5-HT7 receptors by norquetiapine. Ziprasidone at clinical doses blocks reuptake of serotonin, noradrenaline and dopamine, which may suggest the potential for antidepressant properties, but the only ziprasidone trial in bipolar depression indicated this compound had no more efficacy than placebo. 
PHARMACODYNAMICS FOR SGA SAFETY BRAIN

\begin{tabular}{|c|c|}
\hline & BRAIN \\
\hline & 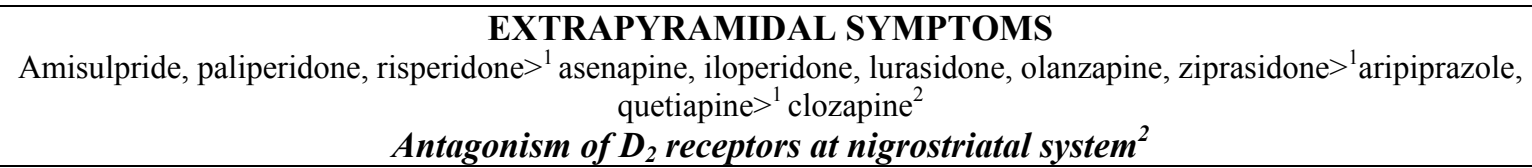 \\
\hline & $\begin{array}{c}\text { HYPERPROLACTINEMIA } \\
\text { Amisulpride, paliperidone, risperidone }>^{1} \text { asenapine, iloperidone ,lurasidone, olanzapine, ziprasidone }>^{1} \text { quetiapine, } \\
\text { clozapine }>^{1} \text { aripiprazole } \\
\text { Antagonism of } D_{2} \text { receptors at tubero-infundibular system }{ }^{4}\end{array}$ \\
\hline & $\begin{array}{c}\text { WEIGHT GAIN } \\
\text { Clozapine, olanzapine }>^{1} \text { asenapine, paliperidone, quetiapine, risperidone }> \\
{ }^{1} \text { amisulpride, aripiprazole, iloperidone, lurasidone, ziprasidone } \\
\left.\text { Antagonism of brain } H_{1} \text { (and others including } 5-H_{2 C} \text { and } M\right) \text { receptors }^{6}\end{array}$ \\
\hline & $\begin{array}{c}\text { SEDATION } \\
\text { Clozapine }>^{1} \text { asenapine, olanzapine }>^{1} \text { quetiapine }>^{1} \text { other } \text { SGAs }^{7} \\
\text { Antagonism of brain } \mathrm{H}_{1} \text { receptors }\end{array}$ \\
\hline & $\begin{array}{c}\text { MEMORY IMPAIRMENT } \\
\text { Possible with clozapine }{ }^{9} \\
\text { Associated with high antagonism of brain muscarinic receptors in schizophrenia patients }{ }^{6}\end{array}$ \\
\hline & $\begin{array}{c}\downarrow \text { SEIZURE THRESHOLD } \\
\text { Clozapine }>^{1} \text { olanzapine, quetiapine }>^{1} \text { other SGAs }{ }^{10} \\
D_{2}, H_{1} \text { and } \alpha_{1} \text { receptor antagonism, actions at neurosteroids or by pharmacological kindling }{ }^{11}\end{array}$ \\
\hline & $\begin{array}{c}\text { OC SYMPTOMS } \\
\text { Clozapine } \\
\text { Antagonism of serotonergic receptors } \\
\end{array}$ \\
\hline & PERIPHERAL (with/without brain component) \\
\hline & $\begin{array}{c}\text { HYPERGLYCEMIA/HYPERLIPIDEMIA } \\
\text { Clozapine, olanzapine, quetiapine }{ }^{12} \\
\text { Secondary to weight gain (see above) } \\
\text { Direct effects on glucose/lipid metabolism }\end{array}$ \\
\hline & $\begin{array}{c}\text { SEXUAL ADRs } \\
\text { Clozapine, risperidone, olanzapine }>^{>} \text {aripiprazole, quetiapine, ziprasidone }{ }^{13} \\
\text { Hyperprolactinemia (see above) and antagonism of peripheral } \boldsymbol{\alpha}, \boldsymbol{M} \text { and } \boldsymbol{H} \text { receptors }{ }^{14}\end{array}$ \\
\hline & $\begin{array}{l}\text { ORTHOSTATIC HYPOTENSION } \\
\text { Clozapine, iloperidone, risperidone, quetiapine, ziprasidone }{ }^{15} \\
\text { Antagonism of peripheral } \boldsymbol{\alpha}_{1} \text { receptors }\end{array}$ \\
\hline & $\begin{array}{c}\text { HYPERTENSION } \\
\text { Clozapine } \\
\text { Not well understood; probably involves noradrenergic mechanisms }\end{array}$ \\
\hline & $\begin{array}{c}\text { ANTICHOLINERGIC SYMPTOMS } \\
\text { (Tachycardia, constipation, dry mouth, urinary retention, or blurred vision) } \\
{ }_{16}^{16} \text { Clozapine }>^{1} \text { olanzapine }>^{1} \text { quetiapine } \\
\text { Antagonism of peripheral muscarinic receptors }\end{array}$ \\
\hline & $\begin{array}{c}\text { NAUSEA } \\
\text { Aripiprazole, lurasidone, ziprasidone } \\
\text { Unknown }\end{array}$ \\
\hline & $\begin{array}{l}\text { SWALLOWING IMPAIRMENT AND ASPIRATION RISK (potentially lethal) } \\
\text { (probably important in intellectual disability and dementia) } \\
\text { Probably all SGAs but not well studied } \\
\text { Unknown }{ }^{18}\end{array}$ \\
\hline & $\begin{array}{l}\text { SUDDEN CARDIAC DEATH ASSOCIATED WITH ARRYTHMIAS (very rare) } \\
\text { Torsades de pointes } \\
\text { Amisulpride, risperidone and ziprasidone }{ }^{19} \\
\text { Antagonism of heart potassium repolarizing } \text { channel }^{20}\end{array}$ \\
\hline & $\begin{array}{c}\text { AGRANULOCYTOSIS } \\
\text { Clozapine }(<1 \%)\end{array}$ \\
\hline
\end{tabular}




\begin{tabular}{|c|}
\hline Probably immunological \\
NEUTROPENIA (very rare) \\
Possibly ALL \\
Unknown \\
\hline RISK FOR VENOUS THROMBOEMBOLISM (very rare) \\
Clozapine $>$ other SGAs $s^{21}$ \\
Not well understood ${ }^{22}$ \\
\hline RISK FOR HEAT STROKE (very rare) \\
Most published cases also involve FGAs ${ }^{23}$ \\
Muscarinic antagonism from antiparkinsonian or from AP (see anticholinergic) inhibits sweating \\
RISK FOR HYPONATREMIA (very rare) \\
There are case reports of both FGAs and SGAs \\
It is difficult to establish the relationship with APs since 2/3 patients had polydipsia \\
LIVER ENZYME ELEVATIONS \\
Clozapine and olanzapine $(<5 \%)>$ probably rare in all other SGAs \\
Unknown
\end{tabular}

Figure 4. Pharmacodynamics of safety for SGAs

5-HT: Serotonin receptor; ADR: Adverse drug reaction; AP: Antipsychotic; D: Dopamine receptor; FGAP: First-generation antipsychotic; H: Histamine receptor; M: Muscarinic receptor; OC: Obsessive-compulsive; SGA: Second-generation antipsychotic. This figure is an update from Figure 5 in a prior article [33]. References were excluded to reduce the total number of references. The second author can provide them to interested readers.

${ }^{1}$ Drugs preceding ">" will produce this ADR more frequently than drugs following ">".

${ }^{2}$ Data from a comprehensive review supplemented with data on asenapine, iloperidone, and lurasidone. There are three major extrapyramidal symptoms: acute dystonic reactions, parkinsonian symptoms and akathisia, which are associated with the same common mechanism of $\mathrm{D}_{2}$ receptor antagonism of the nigrostriatal system, but minor differences may exist among mechanisms and compounds. For example, aripiprazole is thought to have little risk for extrapyramidal symptoms except for akathisia. Any attempt to summarize all 3 extrapyramidal symptoms together is a gross simplification. However, there is not enough meta-analytic data to compare antipsychotics according to their risk for causing acute dystonic reactions, for causing parkinsonian symptoms, or for causing akathisia.

${ }^{3}$ Data from a comprehensive review supplemented with data on asenapine, iloperidone and lurasidone.

${ }^{4}$ All APs are $\mathrm{D}_{2}$ antagonists except aripiprazole, a partial agonist. The lower propensity of SGAs (other than aripiprazole) when compared to FGAs to cause extrapyramidal symptoms is explained by two theories: i) a high ratio between $5-\mathrm{HT}_{2 \mathrm{~A}} / \mathrm{D}_{2}$ receptors, and ii) low affinity and fast dissociation from $\mathrm{D}_{2}$ (only clozapine and quetiapine will be "atypical" since they are displaced by endogenous dopamine).

${ }^{5}$ Data from a comprehensive review supplemented with data on asenapine, iloperidone and lurasidone.

${ }^{6}$ Studies relating weight gain within various APs and receptor affinity indicate that $\mathrm{H}_{1}$ affinity is the best predictor of weight gain. Some animal studies indicate that other receptor (particularly 5- $\mathrm{HT}_{2 \mathrm{C}}$ and muscarinic) antagonism may be needed to produce hyperphagia in animal studies.

${ }^{7}$ Data from a comprehensive review supplemented with data on asenapine and iloperidone.

${ }^{8} \mathrm{H}_{1}$ antagonism is probably the major contributing mechanism to sedation but other receptor antagonism may also contribute. Aripiprazole and ziprasidone have also been associated with early insomnia and activation. It is unknown whether these compounds' pharmacodynamic differences or individual susceptibility explain this activation.

${ }^{9}$ Antagonism of $\mathrm{M}_{1}$ and $\mathrm{M}_{2}$ receptors has been associated with impaired learning and memory in animal studies. It is difficult to detect cognitive impairment in the context of schizophrenia but high antimuscarinic activity was associated with worse memory functioning in an AP meta-analysis. 
Clozapine had a worse profile than risperidone and olanzapine. Clozapine has definitively high antimuscarinic activity. Olanzapine and high doses of quetiapine may also be associated with clinically relevant antimuscarinic activity. Thus, olanzapine and high doses of quetiapine may occasionally be associated with memory impairment.

${ }^{10} \mathrm{~A}$ comprehensive review provided no comparative data on amisulpride, asenapine, iloperidone, or lurasidone.

${ }^{11}$ Proposed mechanisms.

${ }^{12}$ Other SGAs may not have direct effects on glucose or lipid metabolism, but this has not been completely established.

${ }^{13} \mathrm{~A}$ meta-analysis provided no comparative data on amisulpride, asenapine, iloperidone, or lurasidone.

${ }^{14}$ Priapism is rare but is the most severe sexual ADR and is probably explained by $\alpha_{1}$ (and possible $\alpha_{2}$ ) receptor antagonism.

${ }^{15}$ Clozapine, iloperidone, risperidone, quetiapine, and ziprasidone need dose titration to avoid orthostatic hypotension. Orthostatic changes are not seen after intramuscular injections of ziprasidone, so ziprasidone probably has low risk of orthostatic hypotension. Other SGAs with lower risk for orthostatic hypotension are olanzapine (particularly in intramuscular preparation) and asenapine.

${ }^{16}$ Clozapine causes hypersalivation. It is believed that clozapine may be a partial agonist at the $\mathrm{M}_{1}$ and $\mathrm{M}_{3}$ receptors. Norclozapine, clozapine's main metabolite, is definitively an allosteric agonist of $\mathrm{M}_{1}$. In rare cases, severe constipation can lead to AP-induced paralytic ileus and other potentially lethal complications.

${ }^{17}$ Antipsychotics, because of their dopaminergic antagonism, are considered anti-emetic drugs, so it is not known what mechanism explains the association of these three drugs with nausea in the first week of treatment. Other SGAs may also occasionally be associated with nausea.

${ }^{18}$ There are some cases that dysphagia is associated with extrapyramidal symptoms. It is possible that clozapine, due to frequent hypersalivation and high risk for sedation, has greater potential to cause aspiration pneumonia.

${ }^{19} \mathrm{~A}$ recent pharmacoepidemiology study suggested that ziprasidone and amisulpride had potential torsadogenic risk similar to haloperidol and a review of cases reports proposed that risperidone may rarely cause torsades de pointes.

${ }^{20}$ These channels are encoded by the human ether-a-go-go-related gene (HERG).

${ }^{21}$ Based on case reports, a recent review indicated that clozapine may have greater risk than other SGAs.

${ }^{22}$ Several hypotheses have been proposed, such as body weight gain, sedation, enhanced platelet aggregation, increased levels of antiphospholipid antibodies, hyperprolactinemia and hyperhomocysteinemia.

${ }^{23}$ Most published cases including SGAs also had FGAs co-prescribed. 